\title{
Current Status of Infection Control Practice in Surgical Settings of Leading Academic and Private Service Hospitals in Dhaka, Bangladesh
}

\author{
Mohammad Mahabubul Alam 1, *, Mohammad Saiful Islam², Md. Shamsuzzaman Khan³, \\ Shamima Hamid", Md. Nazrul Islam², Mafia Afsin Laz ${ }^{5}$, Shantona Rani Paul ${ }^{6}$ \\ ${ }^{1}$ Department of Pediatric Surgery, Cumilla Medical College, Cumilla, Bangladesh \\ ${ }^{2}$ Department of Pediatric Surgery, Bangabondhu Sheikh Mujib Medical University, Dhaka, Bangladesh \\ ${ }^{3}$ Department of Pediatric Surgery, Shaheed Suhrawardi Medical College, Dhaka, Bangladesh \\ ${ }^{4}$ Department of Pathology, National Institute of Laboratory Medicine \& Refarrel Centre, Dhaka, Bangladesh \\ ${ }^{5}$ Department of Pediatric Surgery, Sir Salimullah Medical College \& Mitford Hospital, Dhaka, Bangladesh \\ ${ }^{6}$ Department of Pediatric Surgery, Rajshahi Medical College, Rajshahi, Bangladesh
}

Email address:

dr.mahbub92@gmail.com (M. M. Alam)

${ }^{*}$ Corresponding author

\section{To cite this article:}

Mohammad Mahabubul Alam, Mohammad Saiful Islam, Md. Shamsuzzaman Khan, Shamima Hamid, Md. Nazrul Islam, Mafia Afsin Laz, Shantona Rani Paul. Current Status of Infection Control Practice in Surgical Settings of Leading Academic and Private Service Hospitals in Dhaka, Bangladesh. International Journal of Infectious Diseases and Therapy. Vol. 6, No. 3, 2021, pp. 97-115.

doi: $10.11648 /$ j.jijidt.20210603.13

Received: June 21, 2021; Accepted: July 5, 2021; Published: August 4, 2021

\begin{abstract}
Health-Care Associated Infection (HCAI) is such a risk and 1.4 millions of people worldwide suffer from HCAIs at any time. To describe the current practice for prevention of health-care associated infections in surgical settings of academic and private hospitals in Dhaka and to propose intervention for improving the conditions with existing resources. This is a descriptive type of exploratory, cross-sectional study and was designed to focus on various dimensions of infection prevention and control that includes- optimum designing of care settings, existing systems, clean-hygienic physical environment and safe practices. This study revealed that uninterrupted water supply and natural ventilation, two basic structural facilities of pivotal importance in infection control engineering were present on all premises under study. However, inadequate toilet and hand washing basins, absence of isolation room, overcrowding of wards was found to pose continuous threat to infection in most of the inpatient wards. Absence of explicit and comprehensive infection control program, clear and current policies on various infection control interventions like hand hygiene, isolation precaution, environmental cleaning, prevention and management of blood borne pathogen, antibiotic usage, injection safety and management of job related illness was revealed from this study. None of the other hospitals maintained post exposure evaluation and follow-up procedures. Although healthcare workers were formally trained in the following matters, unsafe practices for injection, improper use of personal protective equipment, low level of adherence to hand hygiene and cough etiquette were frequently observed during the study. From this study it can be concluded that academic and private hospitals, whether it is government, autonomous or private could not establish the policy, infrastructure, program, processes and safety culture in terms of standard infection prevention and control interventions, except one private service hospital.
\end{abstract}

Keywords: Infection Control, Surgical Settings, Existing Systems, Healthcare System

\section{Introduction}

Healthcare associated infection represents a major public health concern worldwide in terms of mortality, costs and increased length of stay in healthcare settings. Hospitals have played a significant role in the spread of emerging infections. 
Risk of infections are particularly high in some parts of the world, as in South East Asia [1]. Four types of infection accounts for more than $80 \%$ of all healthcare associated infections: respiratory tract infection, surgical-site infection, urinary tract infection and blood stream infection [1]. Over 1.4 million people worldwide suffer from Health-Care Associated Infection (HCAI) at any time [1]. In the developed world about $5-10 \%$ of patients admitted to modern hospitals acquire one or more infections [2]. In the United States, one out of every 136 hospital patients becomes seriously ill as a result of an infection acquired in hospital; this is equivalent to two million cases and about 90,000 deaths in a year [3]. Every year in England, more than 300,000 cases of HCAIs, lead to over 5000 deaths directly attributed to infection and the prevalence of healthcare-associated infections in hospitals in England in 2011 was $6.4 \%$ [4]. The risk of HCAI in developing countries is 2 to 20 times higher than in developed countries; in some countries, the proportion can exceed $25 \%$ [1]. The highest frequencies of HCAIs were reported $11.8 \%$ from hospitals in the Eastern Mediterranean and 10.0\% from south East Asia Regions, with a prevalence of 7.7 and $9.0 \%$ respectively in the European and Western Pacific Regions (Revision of National Hand hygiene Guideline, 2010) [5]. Though exact data is lacking in Bangladesh but it will be at least near to or can more than the South East Asian average. A healthcare-associated infection is a localized or systemic condition resulting from an adverse reaction to the presence of an infectious agent (s) or its toxin (s) that was not present or incubating at the time of admission to the hospital (CDC, 2014). The commonly used medical term for a healthcare-associated infection is "nosocomial" or "hospital-acquired infection". It generally occurs 72 hours after admittance. In 1859, Florence Nightingale, the founder of modern nursing stated; 'It may seem a strange principle to enunciate as the very first requirement in a hospital that it should do the sick no harm' (Nightingale, 1992). Link between healthcare-associated infection prevention practices and the spread of disease has only been established in the last 200 years. During the 1950s, epidemic penicillin-resistant Staphylococcus aureus infections, especially in hospital nurseries, captured the public's attention and highlighted the importance of techniques to prevent hospital-acquired infections. As a result hospital surveillance developed in 1960s and training courses were first offered in the 70s by Center for Disease Control (CDC) [6]. The National Nosocomial Infection Surveillance System (NNIS) was created in the 70s. First Data on Infection Control Efficacy in 1985, the Study of the Efficacy of Nosocomial Infection Control (SENIC) project was published, validating the costbenefit of infection control programs. Data collected in 1970 and 1976-1977 suggested that one-third of all nosocomial infections could be prevented. In 1975 CDC guideline for hand washing and hospital environmental control, in 1986 infection control and in 1995 Association for Professionals in Infection control and Epidemiology (APIC) guideline for hand washing and hand antisepsis health care settings published [6]. The Healthcare Infection Control Practices Advisory Committee (HICPAC) was formed in 1991 by the CDC [7]. Many guidelines have been produced by this group. In 2005 hospitals began contributing data to NHSN (National Healthcare Safety Network) [8, 9]. Development is not always the increasing numbers of facilities rather process of improving the quality. For example increasing the number of beds and wards as well as new building requires large number of investments. Therefore improvement of current systems in terms of policy, practice and process can serve more quality service in existing health care facilities which do not need much extra cost. This may be the actual way of thinking for low-resource countries like Bangladesh. HAIs are a major source of budget drain on the hospital and patients. Limited resources represent the main challenge for governments in developing countries. Such understanding begins with awareness. For awareness to develop study of the current context is elementary. In Bangladesh there are few studies for infection control in hospital settings. One study by Faruquzzaman et al [10], in surgical ward in Dhaka Medical College revealed 30\% of the study patient had suffered from nosocomial infection. Among them $38.7 \%$ was wound infection, $26.6 \%$ urinary tract infection, acute respiratory tract infection $19.2 \%$ and acute gastrointestinal infection was $12.5 \%$. Another significant finding of this study was that there was a strong positive association between the frequency of nosocomial infection and increasing numbers of visitors per patient per day. A study by icddr'b, Dhaka (2012) on "risk of infection from the physical environment in Bangladeshi hospitals: putting infection control into context" on March-September 2007 revealed current situation. This environment posed a threat of infection particularly through contact with contaminated hands, objects or surfaces, to all individuals in the wards, including patients, family caregivers, visitors and hospital staff. Before these two exploratory studies in context of infection control practices a randomized control trial was conducted by Darmstadt et al. [11], from 1998 to 2003 in the Special Care Nursery in Dhaka Shishu hospital in Bangladesh to test the effectiveness of topical emollient therapy in enhancing skin barrier of preterm neonates less than 33 weeks of gestational age. In the initial month of the study, the infection and mortality rates were noted to be unacceptably high. Therefore an infection control program was introduced in January 1999, which was only evident infection prevention and control program since then in the country in any hospital settings. The infection control program was shown to be a simple, low-cost, low-technology intervention to reduce substantially the incidence of septicemia and mortality in the nursery which included emphasis on hand washing, waste disposal, introduction of disposable needles, visitor restriction, cohorting, care of intravenous and urinary catheters, training and supervision and rational antibiotic therapy. Most of the hospitals in Bangladesh do not have visible quality and patient safety activities and these hospitals including the new ones are based on traditional organizational management with no distinct organizational development (OD), perspective and goal. In practice activities seeking competitive advantage in respect of quality and safety does not exist amongst the major public hospitals as well as between public and private hospitals in respect of quality and patient 
safety.

\section{Objectives}

\section{General objective}

To describe the current practice for prevention of healthcare associated infections in surgical settings of academic and private hospitals in Dhaka and to propose intervention for improving the conditions with existing resources.

2. Specific objectives

1. To observe the design considerations of hospitals at planning stage related to infection control practice.

2. To identify the existence of policy and guidelines on infection control.

3. To identify the existence of explicit program for activity of surveillance and prevention of infection in the hospitals.

4. To assess current practices for infection control in clinical care.

5. To observe the workplace practice related to hospital environment for infection control.

6. To observe the demonstrable administrative actions regarding infection control practice.

7. To observe adherence to effective workplace practice and procedures for infection control.

8. To identify the areas for intervention where utilization of existing resources will bring about significant changes.

\section{Materials and Methods}

Study Design: Descriptive type of exploratory cross sectional study.

Place of Study: Academic and private service hospitals in Dhaka, Bangladesh.

1. Bangabandhu Sheikh Mujib Medical University (BSMMU)

2. Bangladesh Institute of Child Health (BICH)

3. Dhaka Medical College\& Hospital (DMCH)

4. Sir Salimullah Medical College\& Mitford Hospital (SSMCH)

5. Bangladesh Institute of Research \& Rehabilitation for Diabetes, Endocrine and Metabolic Disorders (BIRDEM)

6. Apollo Hospitals Dhaka

Period of study: March 2014 to September 2015

Population:

1. Academic and private service hospitals in Dhaka, Bangladesh.

2. Major surgical wards of these six hospital.

3. Health-care workers come in contact with the patient.

Sampling technique: Hospitals are purposively selected by convenience and convenience sampling of wards and healthcare workers.

Sample size:

1. 6 hospitals

2. 50 major surgical wards

3. 150 healthcare workers ( 60 doctors, 60 nurses and 30 auxiliary workers)
Selection criteria:

Inclusion criteria:

1. High volume academic and public service hospitals (more than 450 beds)

2. Institutes that perform procedures on pediatric patient

3. Health-care workers who come in contact with the patient

Exclusion criteria:

Institute not willing to participate in the study

Data Collection tools:

1. Closed type questionnaire filled up by the investigator himself through face to face interview, supplemented by documentary evidence where applicable.

2. Observational data sheet/checklist filled up by the investigator himself after physical observation of surgical wards and interview of healthcare workers.

3. Observation of health-care workers behavior and adoption to infection control practices with an observational data sheet and interview where applicable.

Study Instrument: Questionnaire and observational data sheet were developed based on the infection control surveyor worksheet of Ambulatory Surgical Center of USA (2013) and Infection Prevention Checklist for Outpatient Settings of Division of Healthcare Quality Promotion (DHQP) by CDC (2011). Issues for this studies in context of HCAIs were selected based on feasibility and its impact on safe and reliable healthcare system. Emphasis has been given to concerns that are more common, and routine in the practice culture of our hospitals, as guided by experience and that are considered to be very basic practices and structures to control HCAIs in today's world. The questionnaire and observational data sheet comprised of closed-type questions with 'yes/no' type answers. Rigorous pretesting of the questionnaire was beyond the scope of this study and the questionnaire was only checked for the understandability of the questions and observational data sheets were pretested to check its general applicability into the population.

Data processing and analysis: Statistical Package for Social Sciences (SPSS) v 20 software was used for data entry, and analysis.

Operational definitions:

1. Academic Hospital: Academic hospital is a healthcare providing organization that simultaneously provides formal education and training to healthcare provider.

2. Health-Care Facility: A set of physical infrastructure elements supporting the delivery of health related services. A health-care facility does not include a patient's home or physician offices where health-care may be provided.

3. Health-care Worker $(\mathrm{HCW})$ : All health professionals who are in direct and indirect contact with patients and their environment (e.g. via equipment or product) during their respective activities. Professional categories: 1. Nurse 2. Auxiliary 3. Medical doctor 4. Other health-care worker (Therapist, Technician, Others-----)

4. Infection Prevention and Control (IPC): Evidence- 
based practices and procedures that, when applied consistently in health care settings, can prevent or reduce the risk of transmission of microorganisms to health care providers, other clients/patients/residents and visitors.

5. Infection Prevention and Control Committee (IPACC): The Infection Prevention and Control Committee is a multidisciplinary committee that serves the health care facility and is responsible for verifying that the infection prevention and control recommendations and standards are being followed in the health care facility.

6. Infection Prevention and Control Practioner (s) (ICPs): Trained individual (s) responsible for a healthcare setting's infection prevention and control activities.

7. Infection Prevention and Control Program (IPAC): A health care facility or organization (e.g. hospital, longterm care, continuing complex care, home care) program responsible for meeting the recommended mandate to decrease infections in the patient, health care providers and visitors.

8. Major Surgical Ward: Surgical wards having general, orthopedics, urologic, paediatric, gynecological and neurosurgical patient.

9. Patient: Any person receiving health care within a health-care setting.

10. Patient Contact: (between health-care worker and the patient) refers to the health-care workers hands that touch the patient's skin, clothes and surroundings.

11.Personal Protective Equipment (PPE): Clothing or equipment worn for protection against hazards.

12. Private Service Hospital: It is a private owned hospital where healthcare provider providing service for fee only. High volume hospitals: Hospitals have 450 or more beds.

\section{Observations and Results}

This study was carried out in six leading academic and private service hospitals in Dhaka, namely Bangabandhu Sheikh Mujib Medical University, Dhaka Medical College \& Hospital, Sir Salimullah Medical College \& Mitford Hospital, Bangladesh Institute of Child Health, Bangladesh Institute of Research \& Rehabilitation for Diabetes, Endocrine and Metabolic Disorders (BIRDEM) and Apollo Hospitals, Dhaka. Although the aim of this study is not to compare which hospital is better than the other but to portray true scenario of structure, policies and practices in contexts of HCAIs and identify issues that may be intervened to improve our health-care system, the hospitals have been coded as government, autonomous and private. As pediatric age group comprises a large group of patients and most of the public and private hospitals have limited access to pediatric patients in terms of accommodation. So that a readily accessible public hospital catering solely children was included to bring uniformity the data generated. A total of 50 major surgical ward were observed for the structures related to prevention of HCAIs by an observational data sheet and a total of 150 health-care workers were observed and interviewed based on a preset observational data sheet containing closed-type questions relating to various attributes of practices for prevention of health-care associated infection. The results are displayed through appropriate tables and figures. Type of the facility: Figure 1 shows a total of 6 academic and private service hospitals were observed. Among them 2 were government, 2 were autonomous body and 2 were private hospitals.

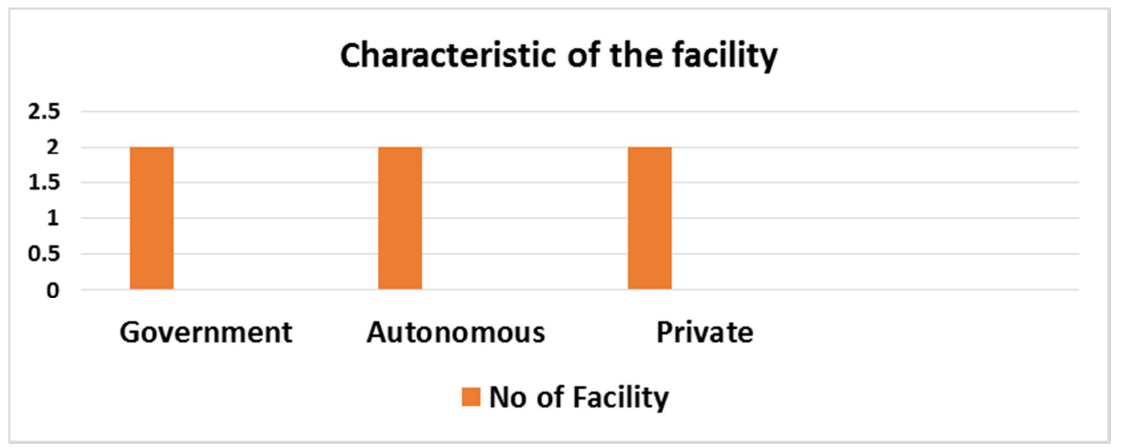

Figure 1. Characteristic of the facility $(n=6)$.

Table 1 shows that maximum number of ( 5 out of 6 ) hospitals were academic hospitals and only 1 was private service hospitals. Both paediatric and adult patients receive care from 5 observed hospitals (83.3\%) and 1 hospital cares for paediatric patients only.

Table 1. Findings of face-to-face interview: characteristics of the facility $(n=6)$.

\begin{tabular}{|c|c|c|c|c|c|c|c|c|}
\hline \multirow{3}{*}{ Findings } & \multicolumn{8}{|c|}{ Type of ownership } \\
\hline & \multicolumn{2}{|c|}{ Government $(n=2)$} & \multicolumn{2}{|c|}{ Autonomous (n=2) } & \multicolumn{2}{|c|}{ Private $(n=2)$} & \multicolumn{2}{|c|}{ Total $(n=6)$} \\
\hline & No. & $\%$ & No. & $\%$ & No. & $\%$ & No. & $\%$ \\
\hline \multicolumn{9}{|c|}{ Age group of patients receiving care from the surveyed hospital } \\
\hline Pediatric & 0 & - & 1 & 50.0 & 0 & - & 1 & 16.7 \\
\hline Adult & 0 & - & 0 & - & 0 & - & & \\
\hline Both & 2 & 100.0 & 1 & 50.0 & 2 & 100.0 & 5 & 83.3 \\
\hline
\end{tabular}


Hospital planning/design considerations at planning stage in context of Infection Control: Table 2 shows that among 6, all the facilities had uninterrupted water supply. $50 \%$ of the facilities had isolation room in ICU and acute care wards and proportion is same in all three categories of hospitals. Ante room before entering the room or ward was found in $2(n=6$, $33.3 \%$ ) facilities.

Table 2. Findings of face to face interview: hospital planning/design considerations at planning stage $(n=6)$.

\begin{tabular}{|c|c|c|c|c|c|c|c|c|}
\hline \multirow{3}{*}{ Findings } & \multicolumn{8}{|c|}{ Type of ownership } \\
\hline & \multicolumn{2}{|c|}{ Government $(n=2)$} & \multicolumn{2}{|c|}{ Autonomous $(n=2)$} & \multicolumn{2}{|c|}{ Private $(n=2)$} & \multicolumn{2}{|c|}{ Total $(n=6)$} \\
\hline & No. & $\%$ & No. & $\%$ & No. & $\%$ & No. & $\%$ \\
\hline \multicolumn{9}{|c|}{ Facility Has Provision For Uninterrupted Water Supply } \\
\hline Yes & 2 & 100.0 & 2 & 100.0 & 2 & 100.0 & 6 & 100.0 \\
\hline No & 0 & 0.0 & 0 & 0.0 & 0 & 0.0 & 0 & 0.0 \\
\hline \multicolumn{9}{|c|}{ Isolation Room In ICU And Acute Care Wards } \\
\hline Yes & 1 & 50.0 & 1 & 50.0 & 1 & 50.0 & 3 & 50.0 \\
\hline \multicolumn{9}{|c|}{ Anteroom Before Entering Room/Ward } \\
\hline Yes & 1 & 50.0 & 1 & 50.0 & 0 & 0.0 & 2 & 33.3 \\
\hline No & 1 & 50.0 & 1 & 50.0 & 2 & 100.0 & 4 & 66.7 \\
\hline
\end{tabular}

Administrative control/Infection Control Program: Table 3 summarizes the current status of infection control program. It shows that among the 6 , all of autonomous and private service hospitals $(66.7 \%)$ had explicit infection control program, but none of the government hospital were mentioned for such program. All autonomous and private hospitals $(66.7 \%)$ among total 6 follow nationally recognized hand hygiene guidelines (2010) of Bangladesh or WHO, 2009 which was not followed by government hospitals (33.3\%). And other internationally recognized prevention and control of infection guidelines were found to follow by private hospitals $(33.3 \%)$. Recommended clear and current policies and procedures to reduce the risk of transmission of infectious agents through hand hygiene was followed by all autonomous and private hospitals $(66.7 \%)$ and by no government hospitals (33.3\%). Both of private hospital $(100 \%)$ had the program and no government hospital $(0 \%)$ mentioned to have such program. Among 3 hospitals who had surveillance program, $100 \%$ of them tracks rates of infection over time to identify trends, reports rates of specific infection to health authorities and shares information on surveillance data with facility leadership. On the other hand $66.7 \%$ of them carried out routine rounds in wards by infection control team. Most of the hospitals (66.7\%) shows existence of a composite waste management system. Only $33.3 \%$ of facilities exists explicit antibiotic policy and antimicrobial resistance campaign. Only private hospitals
$(33.3 \%)$ claimed that, infection control team carries out routine round at all clinical areas. Two thirds of the facilities had an injection safety program and same number $(66.7 \%)$ of the facilities provides health education for all stakeholders. Timely access to microbiology laboratory reports were claimed by $66.7 \%$ of hospitals. Half of the facilities $(50 \%)$ admitted to having system for product review. Most of the facilities $(83.3 \%)$ claimed for existence of monitoring and review of housekeeping. There were routine review of practices for reprocessing of equipments including quality assurance of central sterile supply department in 50\% of facilities. And review of practices for environmental cleaning and spills management was also found in $50 \%$ of hospitals. Only one facility $(16.7 \%)$ could show that, they maintains health status record, immunization and testing of immunization status. Existence of program for action on outbreak detection and management was claimed by most of the hospitals $(66.7 \%)$. Although provision for management of job related illness and exposure to infectious disease, including policies for work restriction for infection or exposed personnel were observed in only $33.3 \%$ facilities (one private and another autonomous). Almost all the facilities provides training to various health-care personnel in aseptic techniques like, universal precaution (100\%), hand hygiene $(100 \%)$, decontamination of items of daily useCheatle, forceps, clinical thermometers, surgical dressings $(100 \%)$ and barrier nursing $(83.3 \%)$.

Table 3. Findings of face to face interview: administrative control/infection control program $(n=6)$.

\begin{tabular}{|c|c|c|c|c|c|c|c|c|}
\hline \multirow{3}{*}{ Findings } & \multicolumn{8}{|c|}{ Type of ownership } \\
\hline & \multicolumn{2}{|c|}{ Government $(n=2)$} & \multicolumn{2}{|c|}{ Autonomous (n=2) } & \multicolumn{2}{|c|}{ Private $(n=2)$} & \multicolumn{2}{|c|}{ Total $(n=6)$} \\
\hline & No. & $\%$ & No. & $\%$ & No. & $\%$ & No. & $\%$ \\
\hline \multicolumn{9}{|c|}{ Explicit infection control program available } \\
\hline Yes & 0 & 0.0 & 2 & 100.0 & 2 & 100.0 & 4 & 66.7 \\
\hline No & 2 & 100.0 & 0 & 0.0 & 0 & 0.0 & 2 & 33.3 \\
\hline \multicolumn{9}{|c|}{ Follow nationally recognized hand hygiene guidelines (2010) of Bangladesh or WHO, 2009} \\
\hline Yes & 0 & 0.0 & 2 & 100.0 & 2 & 100.0 & 4 & 66.7 \\
\hline \multicolumn{9}{|c|}{ Follow other internationally recognized prevention and control of infection guidelines } \\
\hline Yes & 0 & 0.0 & 0 & 0.0 & 2 & 100.0 & 2 & 33.3 \\
\hline No & 2 & 100.0 & 2 & 100.0 & 0 & 0.0 & 4 & 66.7 \\
\hline
\end{tabular}




\begin{tabular}{|c|c|c|c|c|c|c|c|c|}
\hline \multirow{3}{*}{ Findings } & \multicolumn{8}{|c|}{ Type of ownership } \\
\hline & \multicolumn{2}{|c|}{ Government (n=2) } & \multicolumn{2}{|c|}{ Autonomous (n=2) } & \multicolumn{2}{|c|}{ Private $(n=2)$} & \multicolumn{2}{|c|}{ Total $(\mathrm{n}=6)$} \\
\hline & No. & $\%$ & No. & $\%$ & No. & $\%$ & No. & $\%$ \\
\hline Yes & 0 & 0.0 & 1 & 50.0 & 2 & 100.0 & 3 & 50.0 \\
\hline No & 2 & 100.0 & 1 & 50.0 & 0 & 0.0 & 3 & 50.0 \\
\hline \multicolumn{9}{|c|}{ Facilities exists for monitoring and review of housekeeping } \\
\hline Yes & 1 & 50.0 & 2 & 100.0 & 2 & 100.0 & 5 & 83.3 \\
\hline No & 1 & 50.0 & 0 & 0.0 & 0 & 0.0 & 1 & 16.7 \\
\hline \multicolumn{9}{|c|}{ Facilities exists for review of practices for environmental cleaning and spills management } \\
\hline Yes & 1 & 50.0 & 0 & 0.0 & 2 & 100.0 & 3 & 50.0 \\
\hline No & 1 & 50.0 & 2 & 100.0 & 0 & 0.0 & 3 & 50.0 \\
\hline \multicolumn{9}{|c|}{ Maintains health workers health status record, immunization and testing of immunization status } \\
\hline Yes & 0 & 0.0 & 0 & 0.0 & 1 & 50.0 & 1 & 16.7 \\
\hline No & 2 & 100.0 & 2 & 100.0 & 1 & 50.0 & 5 & 83.3 \\
\hline \multicolumn{9}{|c|}{ Program exists for action on outbreak detection and management } \\
\hline Yes & 1 & 50.0 & 1 & 50.0 & 2 & 100.0 & 4 & 66.7 \\
\hline No & 1 & 50.0 & 1 & 50.0 & 0 & 0.0 & 2 & 33.3 \\
\hline \multicolumn{9}{|c|}{$\begin{array}{l}\text { Exists provision for management of job related illness and exposure to infectious disease, including policies for work restriction for infection or expose } \\
\text { personnel }\end{array}$} \\
\hline Yes & 0 & 0.0 & 1 & 50.0 & 1 & 50.0 & 2 & 33.3 \\
\hline No & 2 & 100.0 & 1 & 50.0 & 1 & 50.0 & 4 & 66.7 \\
\hline \multicolumn{9}{|c|}{$\begin{array}{l}\text { Provides training to various healthcare personnel in aseptic techniques } \\
\text { a) Universal precaution }\end{array}$} \\
\hline Yes & 2 & 100.0 & 1 & 50.0 & 1 & 50.0 & 6 & 100.0 \\
\hline No & 0 & 0.0 & 1 & 50.0 & 1 & 50.0 & 0 & 0.0 \\
\hline \multicolumn{9}{|c|}{ b) Hand hygiene } \\
\hline Yes & 2 & 100.0 & 2 & 100.0 & 2 & 100.0 & 6 & 100.0 \\
\hline No & 0 & 0.0 & 0 & 0.0 & 0 & 0.0 & 0 & 0.0 \\
\hline \multicolumn{9}{|c|}{ c) Decontamination of items of daily use Cheatle, forceps, clinical thermometers, surgical dressings } \\
\hline Yes & 2 & 100.0 & 2 & 100.0 & 2 & 100.0 & 6 & 100.0 \\
\hline No & 0 & 0.0 & 0 & 0.0 & 0 & 0.0 & 0 & 0.0 \\
\hline \multicolumn{9}{|c|}{ d) Barrier nursing } \\
\hline Yes & 2 & 100.0 & 1 & 50.0 & 2 & 100.0 & 5 & 83.3 \\
\hline No & 0 & 0.0 & 1 & 50.0 & 0 & 0.0 & 1 & 16.7 \\
\hline
\end{tabular}

Occupational health related practices: Table 4 shows that out of 6 , only one hospital (16.7\%) maintains a log of needle sticks, sharp injuries and other employee exposure events. Furthermore, following an exposure event, post exposure evaluation and follow-up, including prophylaxis as appropriate were available at no cost to employee and are supervised by licensed healthcare professional also in one private hospital and hepatitis $B$ vaccination were found to be available in that only hospital which were confirmed by both interview and physical examination.

Table 4. Occupational health related practices at institute level $(n=6)$.

\begin{tabular}{|c|c|c|c|c|c|c|c|c|}
\hline \multirow{3}{*}{ Findings } & \multicolumn{8}{|l|}{ Type of ownership } \\
\hline & \multicolumn{2}{|l|}{ Government $(n=2)$} & \multicolumn{2}{|c|}{ Autonomous (n=2) } & \multicolumn{2}{|c|}{ Private $(n=2)$} & \multicolumn{2}{|c|}{ Total $(n=6)$} \\
\hline & No. & $\%$ & No. & $\%$ & No. & $\%$ & No. & $\%$ \\
\hline \multicolumn{9}{|c|}{ Hospital maintains a log of needle sticks, sharp injuries and other employee exposure events Practice performed } \\
\hline Yes & 0 & 0.0 & 0 & 0.0 & 1 & 50.0 & 5 & 83.3 \\
\hline No & 2 & 100.0 & 2 & 100.0 & 1 & 50.0 & 1 & 16.7 \\
\hline \multicolumn{9}{|c|}{ Manner of confirmation } \\
\hline $\mathrm{PO}$ & 0 & 0.0 & 1 & 50.0 & 0 & 0.0 & 1 & 16.7 \\
\hline I & 2 & 100.0 & 0 & 0.0 & 1 & 50.0 & 3 & 50.0 \\
\hline B & 0 & 0.0 & 1 & 50.0 & 1 & 50.0 & 2 & 33.3 \\
\hline \multicolumn{9}{|c|}{$\begin{array}{l}\text { Following an exposure event, post exposure evaluation and follow-up, including prophylaxis as appropriate are available at no cost to employee and are } \\
\text { supervised by licensed healthcare professional } \\
\text { Practice performed }\end{array}$} \\
\hline Yes & 0 & 0.0 & 0 & 0.0 & 1 & 50.0 & 1 & 16.7 \\
\hline No & 2 & 100.0 & 2 & 100.0 & 1 & 50.0 & 5 & 83.3 \\
\hline \multicolumn{9}{|c|}{ Manner of confirmation } \\
\hline $\mathrm{PO}$ & 0 & 0.0 & 0 & 0.0 & 0 & 0.0 & 0 & 0.0 \\
\hline I & 2 & 100.0 & 1 & 50.0 & 1 & 50.0 & 4 & 66.7 \\
\hline B & 0 & 0.0 & 1 & 50.0 & 1 & 50.0 & 2 & 33.3 \\
\hline \multicolumn{9}{|c|}{$\begin{array}{l}\text { Hepatitis B vaccination is available at no cost to all employees who are at risk of occupational exposure } \\
\text { Practice performed }\end{array}$} \\
\hline Yes & 0 & 0.0 & 0 & 0.0 & 1 & 50.0 & 1 & 16.7 \\
\hline No & 2 & 100.0 & 2 & 100.0 & 1 & 50.0 & 5 & 83.3 \\
\hline \multicolumn{9}{|c|}{ Manner of confirmation } \\
\hline
\end{tabular}




\begin{tabular}{|c|c|c|c|c|c|c|c|c|}
\hline \multirow{3}{*}{ Findings } & \multicolumn{8}{|c|}{ Type of ownership } \\
\hline & \multicolumn{2}{|c|}{ Government $(n=2)$} & \multicolumn{2}{|c|}{ Autonomous (n=2) } & \multicolumn{2}{|c|}{ Private $(n=2)$} & \multicolumn{2}{|c|}{ Total $(n=6)$} \\
\hline & No. & $\%$ & No. & $\%$ & No. & $\%$ & No. & $\%$ \\
\hline $\mathrm{PO}$ & 0 & 0.0 & 0 & 0.0 & 0 & 0.0 & 0 & 0.0 \\
\hline I & 2 & 100.0 & 2 & 100.0 & 1 & 50.0 & 5 & 83.3 \\
\hline B & 0 & 0.0 & 0 & 0.0 & 1 & 50.0 & 1 & 16.7 \\
\hline \multicolumn{9}{|c|}{ Manner of confirmation } \\
\hline $\mathrm{PO}$ & Phy & & & & & & & \\
\hline I & Inte & & & & & & & \\
\hline $\mathrm{B}$ & Botl & nterview) & & & & & & \\
\hline
\end{tabular}

Surveillance, disease reporting and isolation related practices: Table 5 shows that $50 \%$ of hospital has an updated list of disease reportable to the public health authority is readily available to all personnel, and no government hospital able to show that. Cohorting that means, surgical postoperative patients with wound infections are isolated from other patients were observed in 3 of 6 hospitals.

Table 5. Surveillance and disease reporting related practices at institute level $(n=6)$.

\begin{tabular}{|c|c|c|c|c|c|c|c|c|}
\hline \multirow{3}{*}{ Findings } & \multicolumn{8}{|c|}{ Type of ownership } \\
\hline & \multicolumn{2}{|c|}{ Government (n=2) } & \multicolumn{2}{|c|}{ Autonomous (n=2) } & \multicolumn{2}{|c|}{ Private $(n=2)$} & \multicolumn{2}{|c|}{ Total $(\mathrm{n}=6)$} \\
\hline & No & $\%$ & No. & $\%$ & No. & $\%$ & No. & $\%$ \\
\hline \multicolumn{9}{|c|}{ An updated list of diseases reportable to the public health authority is readily available to all personnel } \\
\hline Yes & 0 & 0.0 & 1 & 50.0 & 2 & 100.0 & 3 & 50.0 \\
\hline No & 2 & 100.0 & 1 & 50.0 & 0 & 0.0 & 3 & 50.0 \\
\hline \multicolumn{9}{|c|}{ Manner of confirmation } \\
\hline $\mathrm{PO}$ & 1 & 50.0 & 0 & 0.0 & 0 & 0.0 & 1 & 16.7 \\
\hline I & 1 & 50.0 & 2 & 100.0 & 1 & 50.0 & 4 & 66.7 \\
\hline B & 0 & 0.0 & 0 & 0.0 & 1 & 50.0 & 1 & 16.7 \\
\hline \multicolumn{9}{|c|}{ Cohorting: surgical postoperative patients with wound infections are isolated from other patients } \\
\hline \multicolumn{9}{|c|}{ Practice performed } \\
\hline Yes & 1 & 50.0 & 1 & 50.0 & 1 & 50.0 & 3 & 50.0 \\
\hline No & 1 & 50.0 & 1 & 50.0 & 1 & 50.0 & 3 & 50.0 \\
\hline \multicolumn{9}{|c|}{ Manner of confirmation } \\
\hline $\mathrm{PO}$ & 0 & 0.0 & 1 & 50.0 & 0 & 0.0 & 1 & 16.7 \\
\hline I & 1 & 50.0 & 1 & 50.0 & 1 & 50.0 & 3 & 50.0 \\
\hline B & 1 & 50.0 & 0 & 0.0 & 1 & 50.0 & 2 & 33.3 \\
\hline \multicolumn{9}{|c|}{ Manner of confirmation } \\
\hline PO & $\mathrm{Phy}$ & & & & & & & \\
\hline I & Inte & & & & & & & \\
\hline B & Bot & nterviev & & & & & & \\
\hline
\end{tabular}

Monitoring of hand hygiene practices at institute level: Table 6 shows that among 6 hospitals only private hospitals (33.3\%) periodically monitors and records adherence to hand hygiene and provides feedback to personnel regarding their performance and this was confirmed by both physical observation and interview mostly $(66.7 \%)$.

Table 6. Hand hygiene related practices at institute level $(n=6)$.

\begin{tabular}{|c|c|c|c|c|c|c|c|c|}
\hline \multirow{3}{*}{ Findings } & \multicolumn{8}{|c|}{ Type of ownership } \\
\hline & \multicolumn{2}{|c|}{ Government $(n=2)$} & \multicolumn{2}{|c|}{ Autonomous $(n=2)$} & \multicolumn{2}{|c|}{ Private $(n=2)$} & \multicolumn{2}{|c|}{ Total $(n=6)$} \\
\hline & No. & $\%$ & No. & $\%$ & No. & $\%$ & No. & $\%$ \\
\hline \multirow{2}{*}{\multicolumn{9}{|c|}{$\begin{array}{l}\text { Hospitals periodically monitors and records adherence to hand hygiene and provides feedback to personnel regarding their performance } \\
\text { Practice nerformed }\end{array}$}} \\
\hline & & & & & & & \multicolumn{2}{|c|}{ Practice performed } \\
\hline Yes & 0 & 0.0 & 0 & 0.0 & 2 & 100.0 & 2 & 33.3 \\
\hline No & 2 & 100.0 & 2 & 100.0 & 0 & 0.0 & 4 & 66.7 \\
\hline \multicolumn{9}{|c|}{ Manner of confirmation } \\
\hline $\mathrm{PO}$ & 0 & 0.0 & 0 & 0.0 & 0 & 0.0 & 0 & 0.0 \\
\hline I & 1 & 50.0 & 0 & 0.0 & 1 & 50.0 & 2 & 33.3 \\
\hline B & 1 & 50.0 & 2 & 100.0 & 1 & 50.0 & 4 & 66.7 \\
\hline \multicolumn{9}{|c|}{ Manner of confirmation } \\
\hline $\mathrm{PO}$ & Phys & & & & & & & \\
\hline I & Inter & & & & & & & \\
\hline B & Both & htervie & & & & & & \\
\hline
\end{tabular}

Availability of personal protective equipment (PPE): Table 7 shows, 4 out of 6 hospitals claimed to have sufficient and appropriate personal protective equipment (PPE) available and readily accessible to healthcare providers. This was confirmed by interview in $66.7 \%$ cases along with physical observation in $33.3 \%$ cases. 
Table 7. Personal protective equipment (PPE) related practices at institute level $(n=6)$.

\begin{tabular}{|c|c|c|c|c|c|c|c|c|}
\hline \multirow{3}{*}{ Findings } & \multicolumn{8}{|c|}{ Type of ownership } \\
\hline & \multicolumn{2}{|c|}{ Government (n=2) } & \multicolumn{2}{|c|}{ Autonomous (n=2) } & \multicolumn{2}{|c|}{ Private $(n=2)$} & \multicolumn{2}{|c|}{ Total $(n=6)$} \\
\hline & No. & $\%$ & No. & $\%$ & No. & $\%$ & No. & $\%$ \\
\hline \multicolumn{9}{|c|}{ Hospitals has sufficient and appropriate PPE available and readily accessible to healthcare providers } \\
\hline \multicolumn{9}{|c|}{ Practice performed } \\
\hline Yes & 1 & 50.0 & 1 & 50.0 & 2 & 100.0 & 4 & 66.7 \\
\hline No & 1 & 50.0 & 1 & 50.0 & 0 & 0.0 & 2 & 33.3 \\
\hline \multicolumn{9}{|c|}{ Manner of confirmation } \\
\hline $\mathrm{PO}$ & 0 & 0.0 & 0 & 0.0 & 0 & 0.0 & 0 & 0.0 \\
\hline I & 2 & 100.0 & 2 & 100.0 & 0 & 0.0 & 4 & 66.7 \\
\hline B & 0 & 0.0 & 0 & 0.0 & 2 & 100.0 & 2 & 33.3 \\
\hline \multicolumn{9}{|c|}{ Manner of confirmation } \\
\hline PO & Phy & & & & & & & \\
\hline I & Inte & & & & & & & \\
\hline B & Bot & nterview) & & & & & & \\
\hline
\end{tabular}

Environmental control of Healthcare Associated Infection: Table 8 shows environmental infection control related practices. Operating rooms are routinely cleaned daily in most of the hospitals ( 5 out of 6 ) and this was confirmed by both interview and physical observation in all hospital. On the other hand high-touch surfaces in patient-care areas were cleaned and disinfected routinely by only private hospitals $(33.3 \%)$. Half of the hospitals claimed that, cleaning procedures are periodically monitored and assessed to ensure that they are consistently and correctly performed.

Table 8. Environmental infection control related practices at institute level $(n=6)$.

\begin{tabular}{|c|c|c|c|c|c|c|c|c|}
\hline \multirow{3}{*}{ Findings } & \multicolumn{8}{|c|}{ Type of ownership } \\
\hline & \multicolumn{2}{|c|}{ Government $(n=2)$} & \multicolumn{2}{|c|}{ Autonomous (n=2) } & \multicolumn{2}{|c|}{ Private $(\mathrm{n}=\mathbf{2})$} & \multicolumn{2}{|c|}{ Total $(\mathrm{n}=6)$} \\
\hline & No. & $\%$ & No. & $\%$ & No. & $\%$ & No. & $\%$ \\
\hline \multicolumn{9}{|c|}{ Operating rooms are routinely cleaned daily } \\
\hline \multicolumn{9}{|c|}{ Practice performed } \\
\hline Yes & 1 & 50.0 & 2 & 100.0 & 2 & 100.0 & 5 & 83.3 \\
\hline No & 1 & 50.0 & 0 & 0.0 & 0 & 0.0 & 1 & 16.7 \\
\hline \multicolumn{9}{|c|}{ Manner of confirmation } \\
\hline $\mathrm{PO}$ & 1 & 50.0 & 0 & 0.0 & 0 & 0.0 & 1 & 16.7 \\
\hline I & 1 & 50.0 & 2 & 100.0 & 1 & 50.0 & 4 & 66.7 \\
\hline B & 0 & 0.0 & 0 & 0.0 & 1 & 50.0 & 1 & 16.7 \\
\hline \multicolumn{9}{|c|}{ Cohorting: surgical postoperative patients with wound infections are isolated from other patients } \\
\hline \multicolumn{9}{|c|}{ Practice performed } \\
\hline Yes & 1 & 50.0 & 1 & 50.0 & 1 & 50.0 & 3 & 50.0 \\
\hline No & 1 & 50.0 & 1 & 50.0 & 1 & 50.0 & 3 & 50.0 \\
\hline \multicolumn{9}{|c|}{ Manner of confirmation } \\
\hline $\mathrm{PO}$ & 0 & 0.0 & 0 & 0.0 & 0 & 0.0 & 0 & 0.0 \\
\hline I & 0 & 0.0 & 0 & 0.0 & 0 & 0.0 & 0 & 0.0 \\
\hline B & 2 & 100.0 & 2 & 100.0 & 2 & 100.0 & 6 & 100.0 \\
\hline \multicolumn{9}{|c|}{ High-touch surfaces in patient care areas are cleaned and disinfected routinely } \\
\hline \multicolumn{9}{|c|}{ Practice performed } \\
\hline Yes & 0 & 0.0 & 0 & 0.0 & 2 & 100.0 & 2 & 33.3 \\
\hline No & 2 & 100.0 & 2 & 100.0 & 0 & 0.0 & 4 & 66.7 \\
\hline \multicolumn{9}{|c|}{ Manner of confirmation } \\
\hline PO & 0 & 0.0 & 0 & 0.0 & 0 & 0.0 & 0 & 0.0 \\
\hline I & 0 & 0.0 & 1 & 50.0 & 0 & 0.0 & 1 & 16.7 \\
\hline B & 2 & 100.0 & 1 & 50.0 & 2 & 100.0 & 5 & 83.3 \\
\hline \multicolumn{9}{|c|}{ Cleaning procedures are periodically monitored and assessed to ensure that they are consistently and correctly performed } \\
\hline Yes & 1 & 50.0 & 0 & 0.0 & 2 & 100.0 & 3 & 50.0 \\
\hline No & 1 & 50.0 & 2 & 100.0 & 0 & 0.0 & 3 & 50.0 \\
\hline \multicolumn{9}{|c|}{ Manner of confirmation } \\
\hline PO & 0 & 0.0 & 0 & 0.0 & 0 & 0.0 & 0 & 0.0 \\
\hline I & 1 & 50.0 & 1 & 50.0 & 1 & 50.0 & 3 & 50.0 \\
\hline B & 1 & 50.0 & 1 & 50.0 & 1 & 50.0 & 3 & 50.0 \\
\hline \multicolumn{9}{|c|}{ Manner of confirmation } \\
\hline PO & Phy & & & & & & & \\
\hline I & Inte & & & & & & & \\
\hline B & Bot & nterview) & & & & & & \\
\hline
\end{tabular}

Safe injection practices at institute level: Table 9 shows that injections are prepared following aseptic technique in a 
clean area free from contact with blood, body fluids or contaminated equipment in all autonomous and private hospitals $(66.7 \%)$. These were confirmed by both physical observation and interview. On the other hand, in all of 6 hospitals medication that were pre-drawn labeled with the date and time of draw, initials of the person drawing medication name, strength and discard date and time were observed.

Table 9. Injection safety related practices at institute level $(n=6)$.

\begin{tabular}{|c|c|c|c|c|c|c|c|c|}
\hline \multirow{3}{*}{ Findings } & \multicolumn{8}{|c|}{ Type of ownership } \\
\hline & \multicolumn{2}{|c|}{ Government $(n=2)$} & \multicolumn{2}{|c|}{ Autonomous (n=2) } & \multicolumn{2}{|c|}{ Private $(n=2)$} & \multicolumn{2}{|c|}{ Total $(n=6)$} \\
\hline & No. & $\%$ & No. & $\%$ & No. & $\%$ & No. & $\%$ \\
\hline \multicolumn{9}{|c|}{ Injections are prepared following aseptic technique in a clean area free from contact with blood, body fluids or contaminated equipment } \\
\hline \multicolumn{9}{|c|}{ Practice performed } \\
\hline Yes & 0 & 0.0 & 2 & 100.0 & 2 & 100.0 & 4 & 66.7 \\
\hline No & 2 & 100.0 & 0 & 0.0 & 0 & 0.0 & 2 & 33.3 \\
\hline \multicolumn{9}{|c|}{ Manner of confirmation } \\
\hline I & 0 & 0.0 & 0 & 0.0 & 0 & 0.0 & 0 & 0.0 \\
\hline B & 2 & 100.0 & 2 & 100.0 & 2 & 100.0 & 6 & 100.0 \\
\hline \multicolumn{9}{|c|}{ Needles are used for only one patient } \\
\hline \multicolumn{9}{|c|}{ Practice performed } \\
\hline Yes & 2 & 100.0 & 2 & 100.0 & 2 & 100.0 & 6 & 100.0 \\
\hline No & 0 & 0.0 & 0 & 0.0 & 0 & 0.0 & 0 & 0.0 \\
\hline \multicolumn{9}{|c|}{ Manner of confirmation } \\
\hline $\mathrm{PO}$ & 0 & 0.0 & 0 & 0.0 & 0 & 0.0 & 0 & 0.0 \\
\hline B & 2 & 100.0 & 2 & 100.0 & 2 & 100.0 & 6 & 100.0 \\
\hline \multicolumn{9}{|c|}{ Syringes are used for only one patients } \\
\hline \multicolumn{9}{|c|}{ Practice performed } \\
\hline Yes & 2 & 100.0 & 2 & 100.0 & 2 & 100.0 & 6 & 100.0 \\
\hline No & 0 & 0.0 & 0 & 0.0 & 0 & 0.0 & 0 & 0.0 \\
\hline \multicolumn{9}{|c|}{ Manner of confirmation } \\
\hline PO & 0 & 0.0 & 0 & 0.0 & 0 & 0.0 & 0 & 0.0 \\
\hline I & 0 & 0.0 & 0 & 0.0 & 0 & 0.0 & 0 & 0.0 \\
\hline B & 2 & 100.0 & 2 & 100.0 & 2 & 100.0 & 6 & 100.0 \\
\hline \multicolumn{9}{|c|}{ Rubber septum on an multi-dose injectable medication vial is disinfection with alcohol prior to piercing } \\
\hline \multicolumn{9}{|c|}{ Practice performed } \\
\hline Yes & 1 & 50.0 & 2 & 100.0 & 2 & 100.0 & 5 & 83.3 \\
\hline No & 1 & 50.0 & 0 & 0.0 & 0 & 0.0 & 1 & 16.7 \\
\hline \multicolumn{9}{|c|}{ Manner of confirmation } \\
\hline $\mathrm{PO}$ & 1 & 50.0 & 0 & 0.0 & 0 & 0.0 & 1 & 16.7 \\
\hline $\begin{array}{l}\text { Medication } \\
\text { Practice pe }\end{array}$ & predr & d time & itials & drawing & cation & trength & iscard & d time \\
\hline Yes & 2 & 100.0 & 2 & 100.0 & 2 & 100.0 & 6 & 100.0 \\
\hline No & 0 & 0.0 & 0 & 0.0 & 0 & 0.0 & 0 & 0.0 \\
\hline Manner of & tion & & & & & & & \\
\hline PO & 0 & 0.0 & 0 & 0.0 & 0 & 0.0 & 0 & 0.0 \\
\hline I & 0 & 0.0 & 0 & 0.0 & 0 & 0.0 & 0 & 0.0 \\
\hline B & 2 & 100.0 & 2 & 100.0 & 2 & 100.0 & 6 & 100.0 \\
\hline All sharps & sed of & p conta & & & & & & \\
\hline Practice pe & & & & & & & & \\
\hline Yes & 0 & 0.0 & 0 & 0.0 & 2 & 100.0 & 2 & 33.3 \\
\hline No & 2 & 100.0 & 2 & 100.0 & 0 & 0.0 & 4 & 66.7 \\
\hline Manner of & tion & & & & & & & \\
\hline PO & 1 & 50.0 & 1 & 50.0 & 0 & 0.0 & 2 & 33.3 \\
\hline I & 0 & 0.0 & 0 & 0.0 & 0 & 0.0 & 0 & 0.0 \\
\hline B & 1 & 50.0 & 1 & 50.0 & 2 & 100.0 & 4 & 66.7 \\
\hline Manner of & tion & & & & & & & \\
\hline $\mathrm{PO}$ & Phy & & & & & & & \\
\hline I & Inte & & & & & & & \\
\hline B & Botl & intervie & & & & & & \\
\hline
\end{tabular}

Respiratory hygiene/cough etiquette related practices at institute level: Table 10 shows that among 6 hospitals posting signs at entrances of ward to cover their mouths/noses when coughing or sneezing were observed in one private hospital. This was confirmed by physical observation only in 3 hospital and by both physical observation and interview in 3 hospital. 
Table 10. Respiratory hygiene/cough etiquette related practices at institute level $(n=6)$.

\begin{tabular}{|c|c|c|c|c|c|c|c|c|}
\hline \multirow{3}{*}{ Findings } & \multicolumn{8}{|c|}{ Type of ownership } \\
\hline & \multicolumn{2}{|c|}{ Government (n=2) } & \multicolumn{2}{|c|}{ Autonomous (n=2) } & \multicolumn{2}{|c|}{ Private $(\mathrm{n}=2)$} & \multicolumn{2}{|c|}{ Total $(n=6)$} \\
\hline & No. & $\%$ & No. & $\%$ & No. & $\%$ & No. & $\%$ \\
\hline \multicolumn{9}{|c|}{ Posting signs at entrances of ward to cover their mouths/noses when coughing or sneezing } \\
\hline \multicolumn{9}{|c|}{ Practice performed } \\
\hline Yes & 0 & 0.0 & 0 & 0.0 & 1 & 50.0 & 1 & 16.7 \\
\hline No & 2 & 100.0 & 2 & 100.0 & 1 & 50.0 & 5 & 83.3 \\
\hline \multicolumn{9}{|c|}{ Manner of confirmation } \\
\hline $\mathrm{PO}$ & 1 & 50.0 & 2 & 100.0 & 0 & 0.0 & 3 & 50.0 \\
\hline I & 0 & 0.0 & 0 & 0.0 & 0 & 0.0 & 0 & \\
\hline B & 1 & 50.0 & 0 & 0.0 & 2 & 100.0 & 3 & 50.0 \\
\hline \multicolumn{9}{|c|}{ Manner of confirmation } \\
\hline PO & Phys & tion & & & & & & \\
\hline I & Inter & & & & & & & \\
\hline B & Both & bservat & tervie & & & & & \\
\hline
\end{tabular}

General observations in the major surgical ward: Table 11 shows that there were one toilet per 8.78 bed $(n=50)$ on an average and range is 3.00-35.00 and one hand washing basin per 12.68 beds $(n=50)$ on an average and range is $0.00-70.00$. An overall mean of 3.02 (range 1.00-6.00) formal and informal caregivers including visitors were observed per 10 $\mathrm{m}^{2}$ area of the ward. Wards in government and autonomous hospitals had an average of 3 times more visitors than private hospitals.

Table 11. General observations at individual ward level.

\begin{tabular}{|c|c|c|c|c|}
\hline \multirow{2}{*}{ Findings } & \multicolumn{4}{|l|}{ Type of ownership } \\
\hline & Government $(\mathrm{n}=\mathbf{2 0})$ & Autonomous (n=14) & Private $(n=16)$ & Total $(n=50)$ \\
\hline \multicolumn{5}{|c|}{ Number of beds per toilet in the ward } \\
\hline Mean \pm SD & $11.10 \pm 6.94$ & $7.86 \pm 2.63$ & $6.69 \pm 2.75$ & $8.78 \pm 5.17$ \\
\hline Range & $6.00-35.00$ & $5.00-12.00$ & $3.00-11.00$ & $3.00-35.00$ \\
\hline \multicolumn{5}{|c|}{ Number of beds per basin } \\
\hline Mean \pm SD & $23.40 \pm 13.69$ & $4.21 \pm 10.14$ & $6.69 \pm 2.96$ & $12.68 \pm 13.48$ \\
\hline Range & $7.00-70.00$ & $0.00-35.00$ & $3.00-11.00$ & $0.00-70.00$ \\
\hline \multicolumn{5}{|c|}{ Number of visitors per 10 sq. $\mathrm{m}$ area of the ward } \\
\hline Mean \pm SD & $3.63 \pm 0.86$ & $3.89 \pm 1.18$ & $1.50 \pm 0.63$ & $3.02 \pm 1.38$ \\
\hline Range & $2.00-5.00$ & $2.00-6.00$ & $1.00-3.00$ & $1.00-6.00$ \\
\hline
\end{tabular}

Structural set up to control infection in the major surgical ward: Table 12 summarizes the structures associated with HCAIs prevention and control practices. Among 50 wards 44 had toilets $(88.0 \%)$ attached with the ward and rest of 6 wards $(12.0 \%)$ having no attached toilet observed from government hospitals. Regarding hand washing basin within the patient-care areas where everyone has access to wash their hands were observed in $68 \%$ of the wards. Toilets and hand washing basins in accessible areas were observed in all private hospitals. While separate clean and dirty corridors were observed in only $38.0 \%$ of wards $(n=50)$. Natural ventilation system were found in 44 wards out of 50 . In $96.0 \%$ of wards color coded waste containers with appropriate labeling were found. 42 wards $(84.0 \%)$ had visitor restriction. Among 50 wards only 12 ward $(24.0 \%)$ had provision of soap and water supplies for hand wash and same number wards $(24.0 \%)$ were found to have alcohol-based hand rub necessary for adherence to hand hygiene and ensured they are readily accessible to healthcare providers in patient-care areas.

Table 12. Structure observed at individual ward level in context of infection control.

\begin{tabular}{|c|c|c|c|c|c|c|c|c|}
\hline \multirow{3}{*}{ Findings } & \multicolumn{8}{|c|}{ Type of ownership } \\
\hline & \multicolumn{2}{|c|}{ Government $(n=20)$} & \multicolumn{2}{|c|}{ Autonomous (n=14) } & \multicolumn{2}{|c|}{ Private $(n=16)$} & \multicolumn{2}{|c|}{ Total $(\mathrm{n}=50)$} \\
\hline & No. & $\%$ & No. & $\%$ & No. & $\%$ & No. & $\%$ \\
\hline \multicolumn{9}{|c|}{ Facility has toilet in every ward } \\
\hline \multicolumn{9}{|c|}{ Practice assessed } \\
\hline Yes & 14 & 70.0 & 14 & 100.0 & 16 & 100.0 & 44 & 88.0 \\
\hline No & 6 & 30.0 & 0 & 0.0 & 0 & 0.0 & 6 & 12.0 \\
\hline \multicolumn{9}{|c|}{ Manner of confirmation } \\
\hline $\mathrm{PO}$ & 1 & 5.0 & 6 & 57.1 & 4 & 25.0 & 13 & 26.0 \\
\hline I & 0 & 0.0 & 0 & 0.0 & 0 & 0.0 & 0 & 0.0 \\
\hline B & 19 & 95.0 & 6 & 42.9 & 12 & 75.0 & 37 & 74.0 \\
\hline \multirow{2}{*}{\multicolumn{9}{|c|}{$\begin{array}{l}\text { Hand washing basin within patient care areas } \\
\text { Practice assessed }\end{array}$}} \\
\hline & & & & & & & & \\
\hline Yes & 15 & 75.0 & 3 & 21.4 & 16 & 100.0 & 34 & 68.0 \\
\hline No & 5 & 25.0 & 11 & 78.6 & 0 & 0.0 & 16 & 32.0 \\
\hline
\end{tabular}




\begin{tabular}{|c|c|c|c|c|c|c|c|c|}
\hline \multirow{3}{*}{ Findings } & \multicolumn{8}{|c|}{ Type of ownership } \\
\hline & \multicolumn{2}{|c|}{ Government $(\mathrm{n}=\mathbf{2 0})$} & \multicolumn{2}{|c|}{ Autonomous (n=14) } & \multicolumn{2}{|c|}{ Private $(n=16)$} & \multicolumn{2}{|c|}{ Total $(\mathrm{n}=\mathbf{5 0})$} \\
\hline & No. & $\%$ & No. & $\%$ & No. & $\%$ & No. & $\%$ \\
\hline \multicolumn{9}{|c|}{ Manner of confirmation } \\
\hline PO & 0 & 0.0 & 8 & 57.1 & 4 & 25.0 & 12 & 24.0 \\
\hline I & 0 & 0.0 & 0 & 0.0 & 0 & 0.0 & 0 & 0.0 \\
\hline B & 20 & 100.0 & 6 & 42.9 & 12 & 75.0 & 38 & 76.0 \\
\hline \multicolumn{9}{|c|}{ Separate clean and dirty corridors } \\
\hline \multicolumn{9}{|c|}{ Practice assessed } \\
\hline Yes & 18 & 90.0 & 1 & 7.1 & 0 & 0.0 & 19 & 38.0 \\
\hline No & 2 & 10.0 & 13 & 92.9 & 16 & 100.0 & 31 & 62.0 \\
\hline \multicolumn{9}{|c|}{ Manner of confirmation } \\
\hline $\mathrm{PO}$ & 7 & 35.0 & 12 & 85.7 & 10 & 62.5 & 29 & 58.0 \\
\hline I & 0 & 0.0 & 0 & 0.0 & 0 & 0.0 & 0 & 0.0 \\
\hline B & 13 & 65.0 & 2 & 14.3 & 6 & 37.5 & 21 & 42.0 \\
\hline \multicolumn{9}{|c|}{ Natural ventilation design compared with standard pattern } \\
\hline \multicolumn{9}{|c|}{ Practice assessed } \\
\hline Yes & 20 & 100.0 & 14 & 100.0 & 10 & 62.5 & 44 & 88.0 \\
\hline No & 0 & 0.0 & 0 & 0.0 & 6 & 37.5 & 6 & 12.0 \\
\hline \multicolumn{9}{|c|}{ Manner of confirmation } \\
\hline PO & 8 & 40.0 & 13 & 92.9 & 10 & 62.5 & 31 & 62.0 \\
\hline I & 0 & 0.0 & 0 & 0.0 & 0 & 0.0 & 0 & 0.0 \\
\hline B & 12 & 60.0 & 1 & 7.1 & 6 & 37.5 & 19 & 38.0 \\
\hline \multicolumn{9}{|c|}{ Color coded waste containers and appropriate labeling } \\
\hline \multicolumn{9}{|c|}{ Practice performed } \\
\hline Yes & 19 & 95.0 & 13 & 92.9 & 16 & 100.0 & 48 & 96.0 \\
\hline No & 1 & 5.0 & 1 & 7.1 & 0 & 0.0 & 2 & 4.0 \\
\hline \multicolumn{9}{|c|}{ Manner of confirmation } \\
\hline $\mathrm{PO}$ & 0 & 0.0 & 8 & 57.1 & 4 & 25.0 & 12 & 24.0 \\
\hline I & 0 & 0.0 & 2 & 14.3 & 0 & 0.0 & 2 & 4.0 \\
\hline $\mathrm{B}$ & 20 & 100.0 & 4 & 28.6 & 12 & 75.0 & 36 & 72.0 \\
\hline \multicolumn{9}{|c|}{ Wards have visitation or visitor restriction } \\
\hline \multicolumn{9}{|c|}{ Practice performed } \\
\hline Yes & 18 & 90.0 & 8 & 57.1 & 16 & 100.0 & 42 & 84.0 \\
\hline No & 2 & 10.0 & 6 & 42.9 & 0 & 0.0 & 8 & 16.0 \\
\hline \multicolumn{9}{|c|}{ Manner of confirmation } \\
\hline PO & 0 & 0.0 & 3 & 921.4 & 2 & 12.5 & 5 & 10.0 \\
\hline I & 0 & 0.0 & 6 & 42.9 & 0 & 0.0 & 6 & 12.0 \\
\hline B & 20 & 100.0 & 5 & 35.7 & 14 & 87.5 & 39 & 78.0 \\
\hline
\end{tabular}

The facility provides supplies necessary for adherence to hand-hygiene and ensures they are readily accessible to healthcare providers in patient care areas a) Soap and water supply Practice assessed

\begin{tabular}{|c|c|c|c|c|c|c|c|c|}
\hline Yes & 2 & 10.0 & 1 & 7.1 & 9 & 56.3 & 12 & 24.0 \\
\hline No & 18 & 90.0 & 13 & 92.9 & 7 & 43.6 & 38 & 76.0 \\
\hline \multicolumn{9}{|c|}{ Manner of confirmation } \\
\hline $\mathrm{PO}$ & 0 & 0.0 & 2 & 14.3 & 4 & 25.0 & 6 & 12.0 \\
\hline I & 0 & 0.0 & 5 & 35.7 & 0 & 0.0 & 5 & 10.0 \\
\hline $\mathrm{B}$ & 20 & 100.0 & 7 & 50.0 & 12 & 75.0 & 39 & 78.0 \\
\hline \multicolumn{9}{|c|}{ b) Alcohol-based hand rub } \\
\hline \multicolumn{9}{|c|}{ Practice assessed } \\
\hline Yes & 0 & 0.0 & 2 & 14.3 & 10 & 62.5 & 12 & 24.0 \\
\hline No & 20 & 100.0 & 12 & 85.7 & 6 & 375 & 38 & 76.0 \\
\hline \multicolumn{9}{|c|}{ Manner of confirmation } \\
\hline $\mathrm{PO}$ & 0 & 0.0 & 0 & 0.0 & 4 & 25.0 & 4 & 8.0 \\
\hline I & 0 & 0.0 & 5 & I 35.7 & 0 & 0.0 & 5 & 10.0 \\
\hline B & 20 & 100.0 & 9 & 64.3 & 12 & 75.0 & 41 & 82.0 \\
\hline
\end{tabular}

Manner of confirmation

PO Physical observation

I Interview

B Both (physical observation and interview)

Level of adherence to hand hygiene among healthcare workers $(n=150)$ : Table 13 summarizes the hand hygiene related behaviour of individual healthcare workers during observation period. Among 150 healthcare workers, 128 $(85.3 \%)$ washed their hand after removing gloves. There was no significant difference between government, private and autonomous healthcare facilities. Only $22 \mathrm{HCWs}(\mathrm{n}=150$, $14.7 \%$ ) observed to perform hand hygiene before direct patient contact. These were confirmed by only physical interview in $34 \%$ individuals, from interview in $10 \%$ individuals and both physical examination and interview in $56 \%$ individuals. On the other hand after direct patient 
contact $28 \% \quad(n=150)$ HCWs claimed and observed to perform hand hygiene which was confirmed most of times $(89.4 \%)$ by physical observation. Nearly half of the healthcare workers $(n=150,47.3 \%)$ maintained hand hygiene before performing invasive procedure (e.g. placing an I. V. cannula). It was assessed through direct observation most of the times $(89.4 \%)$. It was also observed that even after contact with blood, body fluids, or contaminated surfaces 9 healthcare workers $(n=150,6 \%)$ was not seen to wash their hands although most of them (94\%) claimed and observed to do that. Less than half of the healthcare workers $(n=150$, $46.0 \%$ ) wear gloves for procedures that might involve contact with blood or body fluids. On the other hand, among
150 healthcare workers $113(75.3 \%)$ claimed and observed to wear gloves when handling potentially contaminated patient equipment. Result were confirmed by both physical observation and interview, only interview and only physical observation in $42.7 \%, 34.7 \%$ \& $22.7 \%$ events respectively. $128(85.3 \%)$ of them were claimed and also observed to remove gloves before moving to the next task and/or patient. $71.3 \%$ of healthcare providers $(n=150)$ mentioned that they were educated regarding appropriate indications for hand washing with soap and water versus hand rubbing with alcohol-based hand rub and it were based on interview principally $(97.3 \%)$.

Table 13. Hand hygiene at healthcare workers individual level $(n=150)$.

\begin{tabular}{|c|c|c|c|c|c|c|c|c|}
\hline \multirow{3}{*}{ Findings } & \multicolumn{8}{|c|}{ Type of ownership } \\
\hline & \multicolumn{2}{|c|}{ Government $(n=57)$} & \multicolumn{2}{|c|}{ Autonomous (n=49) } & \multicolumn{2}{|c|}{ Private $(n=44)$} & \multicolumn{2}{|c|}{ Total $(n=150)$} \\
\hline & No. & $\%$ & No. & $\%$ & No. & $\%$ & No. & $\%$ \\
\hline \multicolumn{9}{|c|}{ Staff perform hand hygiene } \\
\hline \multicolumn{9}{|c|}{ a) After removing gloves } \\
\hline \multicolumn{9}{|c|}{ Practice performed } \\
\hline Yes & 46 & 80.7 & 47 & 95.9 & 35 & 79.5 & 128 & 85.3 \\
\hline No & 11 & 19.3 & 2 & 4.1 & 9 & 20.5 & 22 & 14.7 \\
\hline PO & 21 & 36.8 & 15 & 30.6 & 7 & 15.9 & 43 & 28.7 \\
\hline I & 9 & 15.8 & 4 & 8.2 & 15 & 34.1 & 28 & 18.7 \\
\hline B & 27 & 47.4 & 30 & 61.2 & 22 & 50.0 & 79 & 52.7 \\
\hline \multicolumn{9}{|c|}{ b) Before direct patient contact } \\
\hline \multicolumn{9}{|c|}{ Practice performed } \\
\hline Yes & 8 & 14.0 & 3 & 6.1 & 11 & 25.0 & 22 & 14.7 \\
\hline No & 49 & 86.0 & 46 & 93.9 & 33 & 75.0 & 128 & 85.3 \\
\hline $\mathrm{PO}$ & 25 & 43.9 & 17 & 34.7 & 9 & 20.5 & 51 & 34.0 \\
\hline I & 4 & 7.0 & 1 & 2.0 & 10 & 22.7 & 15 & 10.0 \\
\hline B & 28 & 49.1 & 31 & 63.3 & 25 & 56.8 & 84 & 56.0 \\
\hline \multicolumn{9}{|c|}{ c) After direct patient contact } \\
\hline \multicolumn{9}{|c|}{ Practice performed } \\
\hline Yes & 11 & 19.3 & 5 & 10.2 & 26 & 59.1 & 42 & 28.0 \\
\hline No & 46 & 80.7 & 44 & 89.8 & 18 & 40.9 & 108 & 72.0 \\
\hline \multicolumn{9}{|c|}{ Manner of confirmation } \\
\hline $\mathrm{PO}$ & 24 & 42.1 & 17 & 34.7 & 8 & 18.2 & 49 & 32.7 \\
\hline I & 5 & 8.8 & 1 & 2.0 & 10 & 22.7 & 16 & 10.7 \\
\hline B & 28 & 49.1 & 31 & 63.3 & 26 & 59.1 & 85 & 56.7 \\
\hline \multicolumn{9}{|c|}{ d) Before performing invasive procedure (e.g. placing an intravenous cannula) } \\
\hline \multicolumn{9}{|c|}{ Practice performed } \\
\hline Yes & 12 & 21.1 & 29 & 59.2 & 30 & 68.2 & 71 & 47.3 \\
\hline No & 45 & 78.9 & 20 & 40.8 & 14 & 31.8 & 79 & 52.7 \\
\hline \multicolumn{9}{|c|}{ Manner of confirmation } \\
\hline $\mathrm{B}$ & 32 & 561 & 29 & 59.2 & 24 & 54.5 & 85 & 56.7 \\
\hline \multicolumn{9}{|c|}{ e) After contact with blood, body fluids, or contaminated surfaces } \\
\hline Practice $\mathrm{p}$ & & & & & & & & \\
\hline Yes & 52 & 91.2 & 46 & 93.9 & 43 & 97.7 & 141 & 94.0 \\
\hline No & 5 & 8.8 & 3 & 6.1 & 1 & 2.3 & 9 & 6.0 \\
\hline Manner o & tion & & & & & & & \\
\hline PO & 13 & 22.8 & 9 & 18.4 & 5 & 11.4 & 27 & 18.0 \\
\hline I & 20 & 35.1 & 9 & 18.4 & 18 & 40.9 & 47 & 31.3 \\
\hline B & 24 & 42.1 & 31 & 63.3 & 21 & 47.7 & 78 & 50.7 \\
\hline Regarding & aff & & & & & & & \\
\hline a) Wear g & roced & ght inv & ct wit & ody fl & & & & \\
\hline Practice $p$ & & & & & & & & \\
\hline Yes & 19 & 33.3 & 18 & 36.7 & 32 & 72.7 & 69 & 46.0 \\
\hline No & 38 & 66.7 & 31 & 63.3 & 12 & 27.3 & 81 & 54.0 \\
\hline Manner o & tion & & & & & & & \\
\hline
\end{tabular}




\begin{tabular}{|c|c|c|c|c|c|c|c|c|}
\hline \multirow{3}{*}{ Findings } & \multicolumn{8}{|c|}{ Type of ownership } \\
\hline & \multicolumn{2}{|c|}{ Government $(n=57)$} & \multicolumn{2}{|c|}{ Autonomous (n=49) } & \multicolumn{2}{|c|}{ Private $(n=44)$} & \multicolumn{2}{|c|}{ Total $(n=150)$} \\
\hline & No. & $\%$ & No. & $\%$ & No. & $\%$ & No. & $\%$ \\
\hline $\mathrm{PO}$ & 22 & 38.6 & 17 & 34.7 & 8 & 18.2 & 47 & 31.3 \\
\hline I & 8 & 14.0 & 2 & 4.1 & 13 & 29.5 & 23 & 15.3 \\
\hline B & 27 & 47.4 & 30 & 61.2 & 23 & 52.3 & 80 & 53.3 \\
\hline \multirow{2}{*}{\multicolumn{9}{|c|}{$\begin{array}{l}\text { b) Wear gloves when handling potentially contaminated patient equipment } \\
\text { Practice performed }\end{array}$}} \\
\hline & & & & & & & & \\
\hline Yes & 38 & 66.7 & 35 & 71.4 & 40 & 90.9 & 113 & 75.3 \\
\hline No & 19 & 33.3 & 14 & 28.6 & 4 & 9.1 & 37 & 24.7 \\
\hline \multicolumn{9}{|c|}{ Manner of confirmation } \\
\hline PO & 18 & 31.6 & 12 & 24.5 & 4 & 9.1 & 34 & 22.7 \\
\hline I & 22 & 38.6 & 9 & 18.4 & 21 & 47.7 & 52 & 34.7 \\
\hline B & 17 & 29.8 & 28 & 57.1 & 19 & 43.2 & 64 & 42.7 \\
\hline \multicolumn{9}{|c|}{ c) Remove gloves before moving to the next task and/or patient } \\
\hline \multicolumn{9}{|c|}{ Practice performed } \\
\hline Yes & 48 & 84.2 & 40 & 81.6 & 40 & 90.9 & 128 & 85.3 \\
\hline No & 9 & 15.8 & 9 & 18.4 & 4 & 9.1 & 22 & 14.7 \\
\hline \multicolumn{9}{|c|}{ Manner of confirmation } \\
\hline PO & 15 & 26.3 & 7 & 14.3 & 5 & 11.4 & 27 & 18.0 \\
\hline I & 18 & 31.6 & 11 & 22.4 & 16 & 36.4 & 45 & 30.0 \\
\hline B & 24 & 42.1 & 31 & 63.3 & 23 & 52.3 & 78 & 52.0 \\
\hline \multicolumn{9}{|c|}{$\begin{array}{l}\text { d) Healthcare providers are educated regarding appropriate indications forhandwashing with soap and water versus hand rubbing with } \\
\text { alcohol-basedhandrub }\end{array}$} \\
\hline \multicolumn{9}{|c|}{ Practice performed } \\
\hline Yes & 39 & 68.4 & 35 & 71.4 & 33 & 75.0 & 107 & 71.3 \\
\hline No & 18 & 31.6 & 14 & 28.6 & 11 & 25.0 & 43 & 28.7 \\
\hline \multicolumn{9}{|c|}{ Manner of confirmation } \\
\hline PO & 2 & 3.5 & 0 & 0.0 & 0 & 0.0 & 2 & 1.3 \\
\hline I & 55 & 96.5 & 47 & 95.9 & 44 & 100.0 & 146 & 97.3 \\
\hline B & 0 & 0.0 & 2 & 4.1 & 0 & 0.0 & 2 & 1.3 \\
\hline \multicolumn{9}{|c|}{ Manner of confirmation } \\
\hline $\mathrm{PO}$ & Phys & ation & & & & & & \\
\hline I & Inter & & & & & & & \\
\hline $\mathrm{B}$ & Both & bserva & tervie & & & & & \\
\hline
\end{tabular}

Practice related to personal protective equipment: Table 14 shows that among 150 healthcare providers 95 (63.3\%) of them claimed that they received training on proper selection and use of personal protective equipment and those were confirmed by personal interview (98.0\%). Furthermore, more than half of the healthcare providers $(56.0 \%)$ were observed to wear PPE (e.g. gloves, masks, gowns etc.) properly. Both physical examination and interview were the method of confirmation for practice in $48.0 \%$ cases and only physical observation in $(46.7 \%)$ cases.

Table 14. Personal protective equipment practice at the individual level $(n=150)$.

\begin{tabular}{|c|c|c|c|c|c|c|c|c|}
\hline \multirow{3}{*}{ Findings } & \multicolumn{8}{|c|}{ Type of ownership } \\
\hline & \multicolumn{2}{|c|}{ Government $(n=57)$} & \multicolumn{2}{|c|}{ Autonomous $(n=49)$} & \multicolumn{2}{|c|}{ Private $(n=44)$} & \multicolumn{2}{|c|}{ Total $(n=150)$} \\
\hline & No. & $\%$ & No. & $\%$ & No. & $\%$ & No. & $\%$ \\
\hline \multicolumn{9}{|c|}{ Healthcare providers receive training on proper selection and use of PPE } \\
\hline \multicolumn{9}{|c|}{ Practice performed } \\
\hline Yes & 35 & 61.4 & 32 & 65.3 & 28 & 63.6 & 95 & 63.3 \\
\hline No & 22 & 38.6 & 17 & 34.7 & 16 & 36.4 & 55 & 36.7 \\
\hline \multicolumn{9}{|c|}{ Manner of confirmation } \\
\hline I & 56 & 98.2 & 47 & 95.9 & 44 & 100.0 & 147 & 98.0 \\
\hline B & 0 & 0.0 & 2 & 4.1 & 0 & 0.0 & 2 & 1.3 \\
\hline \multicolumn{9}{|c|}{$\begin{array}{l}\text { The healthcare providers wearing PPE properly or not (a) gloves, (b) masks, (c) outer garments (gowns, aprons, lab coats, surgical upper hoods, shoe } \\
\text { covers and booties) }\end{array}$} \\
\hline \multicolumn{9}{|c|}{ Practice performed } \\
\hline Yes & 27 & 47.4 & 27 & 55.1 & 30 & 68.2 & 84 & 56.0 \\
\hline No & 30 & 52.6 & 22 & 44.9 & 14 & 31.8 & 66 & 44.0 \\
\hline \multicolumn{9}{|c|}{ Manner of confirmation } \\
\hline I & 1 & 1.8 & 0 & 0.0 & 7 & 15.9 & 8 & 5.3 \\
\hline B & 22 & 38.6 & 29 & 59.2 & 21 & 47.7 & 72 & 48.0 \\
\hline \multicolumn{9}{|c|}{ Manner of confirmation } \\
\hline PO & Phys & ation & & & & & & \\
\hline I & Inter & & & & & & & \\
\hline $\mathrm{B}$ & Both & bserva & tervi & & & & & \\
\hline
\end{tabular}


Practice related to handling of biological products and respiratory hygiene: Table 15 shows that using utility gloves during handling of biological products and contaminated instruments among healthcare workers were observed in only $19.3 \%$ cases $(\mathrm{n}=150)$. During observation period 57 healthcare workers $(n=150,38.0 \%)$ covered their cough every time. Appropriate color-coded waste container for waste materials of different categories were used by 43 $(n=150,28.7 \%)$ healthcare workers.

Table 15. Handling of biological products and respiratory hygiene $(n=150)$.

\begin{tabular}{|c|c|c|c|c|c|c|c|c|}
\hline \multirow{3}{*}{ Findings } & \multicolumn{8}{|c|}{ Type of ownership } \\
\hline & \multicolumn{2}{|c|}{ Government $(n=57)$} & \multicolumn{2}{|c|}{ Autonomous $(n=49)$} & \multicolumn{2}{|c|}{ Private $(n=44)$} & \multicolumn{2}{|c|}{ Total $(n=150)$} \\
\hline & No. & $\%$ & No. & $\%$ & No. & $\%$ & No. & $\%$ \\
\hline \multicolumn{9}{|c|}{ Healthcare workers use utility gloves during handling of biological products and contaminated instruments } \\
\hline \multicolumn{9}{|c|}{ Practice performed } \\
\hline Yes & 3 & 5.3 & 2 & 4.1 & 24 & 54.5 & 29 & 19.3 \\
\hline No & 54 & 94.7 & 47 & 95.9 & 20 & 45.5 & 121 & 80.7 \\
\hline \multicolumn{9}{|c|}{ Manner of confirmation } \\
\hline I & 22 & 38.6 & 9 & 18.4 & 29 & 65.9 & 60 & 40.0 \\
\hline B & 28 & 49.1 & 29 & 59.2 & 13 & 29.5 & 70 & 46.7 \\
\hline \multicolumn{9}{|c|}{ The healthcare workers cover their cough every time } \\
\hline \multicolumn{9}{|c|}{ Practice performed } \\
\hline Yes & 23 & 40.4 & 15 & 30.6 & 19 & 43.2 & 57 & 38.0 \\
\hline No & 34 & 59.6 & 34 & 69.4 & 25 & 56.8 & 93 & 62.0 \\
\hline \multicolumn{9}{|c|}{ Manner of confirmation } \\
\hline I & 7 & 12.3 & 4 & 8.2 & 17 & 38.6 & 28 & 18.7 \\
\hline B & 24 & 42.1 & 33 & 67.3 & 24 & 54.5 & 81 & 54.0 \\
\hline \multicolumn{9}{|c|}{ All healthcare providers use appropriate color-coded waste containers for waste materials of different categories } \\
\hline \multicolumn{9}{|c|}{ Practice performed } \\
\hline Yes & 20 & 35.1 & 5 & 10.2 & 18 & 40.9 & 43 & 28.7 \\
\hline No & 37 & 64.9 & 44 & 89.8 & 26 & 59.1 & 107 & 71.3 \\
\hline \multicolumn{9}{|c|}{ Manner of confirmation } \\
\hline PO & 12 & 21.1 & 8 & 16.3 & 5 & 11.4 & 25 & 16.7 \\
\hline I & 10 & 17.5 & 2 & 4.1 & 13 & 29.5 & 25 & 16.7 \\
\hline B & 35 & 61.4 & 39 & 79.6 & 26 & 59.1 & 100 & 66.7 \\
\hline \multicolumn{9}{|c|}{ Manner of confirmation } \\
\hline $\mathrm{PO}$ & Phys & ation & & & & & & \\
\hline I & Inter & & & & & & & \\
\hline $\mathrm{B}$ & Both & bserva & atervi & & & & & \\
\hline
\end{tabular}

Categories of Healthcare Workers: Table 16 and Figure 2 shows that among observed 150 healthcare workers 60 (40\%) were doctor, 60 (40\%) were nurse and $30(20 \%)$ were auxiliary worker.

Table 16. Hospital personnel observed and interviewed $(n=150)$.

\begin{tabular}{|c|c|c|c|c|c|c|c|c|}
\hline \multirow{3}{*}{ Findings } & \multicolumn{8}{|c|}{ Type of ownership } \\
\hline & \multicolumn{2}{|c|}{ Government $(n=57)$} & \multicolumn{2}{|c|}{ Autonomous $(\mathrm{n}=49)$} & \multicolumn{2}{|c|}{ Private $(n=44)$} & \multicolumn{2}{|c|}{ Total $(n=150)$} \\
\hline & No. & $\%$ & No. & $\%$ & No. & $\%$ & No. & $\%$ \\
\hline Auxiliary worker & 12 & 21.1 & 10 & 20.4 & 8 & 18.2 & 30 & 20 \\
\hline Nurse & 24 & 42.1 & 18 & 36.7 & 18 & 40.9 & 60 & 40 \\
\hline Doctor & 21 & 36.8 & 21 & 42.9 & 18 & 40 & 60 & 40 \\
\hline
\end{tabular}

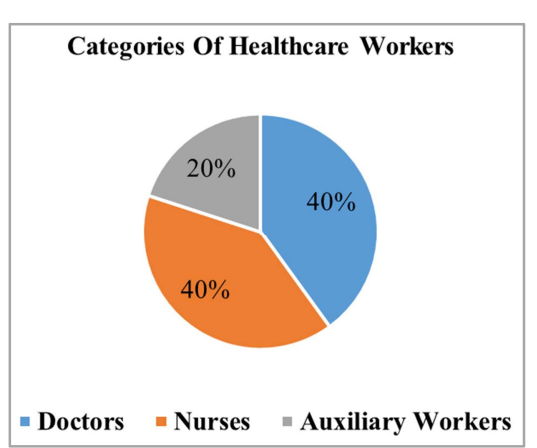

Figure 2. Healthcare workers observed and interviewed.
The results have been presented to display the descriptive statistics. No analysis was done to see the difference between various hospitals as it was not the motive.

\section{Discussion}

Healthcare can and does save lives. It has brought unprecedented benefits to generations of patients and caregivers. However, it also carries formidable risks. Healthcare in fact is a two-sided coin where success and failure exists together. Infections similarly are a double-faced coin. On one side, its prevention and control has saved 
millions of life at all ages and immensely contributed to longevity of mankind. On the other hand, its current resurgence in many forms not only threatens life of many hundreds and thousands of patients in hospital settings but also tends to increase the morbidity and healthcare burden. Therefore a war seems to be logical and is ongoing to fight infections everywhere. In this perspective despite the proven benefits of infection control practices in developed countries, conscious efforts are seldom visible and there is little documentation of successful infection control efforts in the developing world in scientific literature [1]. Presumably, the rates of healthcare associated infection remain unacceptably high and continue to contribute to healthcare and economic burden. Lack of noticeable and significant researches and articles in print and electronic media pertaining to infection control priorities, policies and practices in Bangladesh proclaim the necessity of study of infection control affairs in the country. This study has emerged from the need to address such an important issue of healthcare relevance that is somewhat silently prevalent in our healthcare system. The study was designed to focus on various dimensions of infection prevention and control that includes- optimum designing of care settings, policies and control systems, state of physical environment in terms of its cleanliness and hygienic attributes and safe practices. The study included organizations, major surgical hospital wards and healthcare workers practically engaged in the major surgical wards of six academic and private service hospitals in Dhaka as primary subjects. In this connection it was witnessed that most of the private hospitals do not have a formal academic role whereas most of the public hospitals have such role. A total of six academic and private service hospitals (including equal number of government, autonomous and private hospitals) participated in the study. 50 major surgical wards were observed for infrastructure and physical environment. And a total of 150 healthcare workers (including 60 doctors, 60 nurses and 30 auxiliary workers) were observed at work. All the hospitals provided care to both adult and pediatric patients, except one which cared for pediatric patients only. The first issue studied in this research was design considerations of hospitals at planning stage with a view to controlling and preventing infections. It has been concluded from rigorous studies elsewhere that the physical environment has critical or strategic role in prevention and control of HCAIs [12]. It has been revealed from such studies that natural ventilations, uninterrupted water supply, hand washing basins, adequate toilets and isolation facilities comprise important bricks in the wall against infection control [13]. All the hospital buildings demonstrated good natural ventilation system. Observably, these hospitals did not isolate surgical post-operative patients with wound infections from other patients. It has been ascertained that isolation of infected personnel from healthy and vulnerable persons is essential and beneficial for clinical safety and it is also possible in the context existing in Bangladeshi, as mentioned by Hasan $Z$ et al [14]. Crowding in hospitals facilitates the spread of number of infectious diseases either by direct contact or by airborne or droplet transmission [15]. Absence of entry room at entrance point of the wards as well as single rooms in the construction design allowed visitors to enter freely to the wards without barrier. The number (a median of 3.2 persons) of visitors per 10 sq. meter area of the study wards seen in this study was found to be three times higher compared to a study conducted in a Singapore hospital (a median of 0.5 to one person). This is similar to the finding in other Bangladeshi hospitals, as was found (a median of 3.7 persons) in cross sectional study of three tertiary government hospitals [16]. Overcrowding of visitors, in the wards observed, have potentials to influence prevalence of hospital acquired infection in surgical wards. It was noted in a study of Bangladeshi academic public hospitals that in surgical and burn wards, the rate of infections significantly increased as the number of visitors [10]. WHO recommends au fait actions, with regard to water, basic sanitation and natural waste management in health-care settings in order to ensure the safe environment needed for safe healthcare outcomes and to provide support to healthcare providers for the safe disposal of the waste is generated by healthcare. In our study two thirds of hospitals mentioned to have a composite waste management system. In almost all the wards there were color coded waste container with appropriate labeling. But it was found that a quarter of healthcare workers in a particular premise used these color-coded waste containers for disposing waste materials of different categories. Observably public hospitals which are both academic and tertiary at level of care do not comply with such proven and practicable practices in tertiary settings [3]. This is also true for all other infection control activities. Observations on injection safety unveiled some remarkable facts. Two thirds of the hospitals however claimed to have an injection safety program, when verified on ground this could be confirmed from the official sources. At the same time systems for supervising and monitoring the program was not seen except in a private hospital. Most of the hospitals admitted not to have an explicit antibiotic policy and an antimicrobial campaign. However, standard practices like preparing the injections in aseptic technique in clean area, using single needle for each patient and for every injection, disinfecting rubber septum of multi-dose vials, labeling of pre-drawn medication with the date and time of drawl, initials of the person drawing, name and strength of medication and their expiry date was seen to be in practice on site in most of the hospitals. These methods were also seen to be practiced in primary levels hospitals in Bangladesh in a study by Shill M C et al [17]. In addition to these, the practice of disposal of sharps, in a puncture resistant sharps container was also not observed in any public and autonomous hospitals. These continuously pose the healthcare workers to a thread to needle stick injury (NSI). This risk was verified in a study conducted by Shill et al. [17], in Upazila Health Complexes of Bangladesh where 22\% HCWs mentioned to experience needle stick injury during study period. Here it is seen that healthcare workers are also unaware about their own safety. From this it can be concluded from these findings that good practices that were 
seen in reality were more ritualistic rather derived from an all-encompassing concept and culture of healthcare safety. However, these findings were not confirmed on ground and the stated result are reported from face to face interview particularly in respect of compliance. Therefore is to be interpreted with caution. But an admittance by $50 \%$ of the facilities that they do not observe such verification practices is important to notice from the view point of patient safety. Demonstrable leadership, steering infection control program, by a senior administrator was not seen in any of public hospitals. There was neither a position for nor an Infection Control PR actioner (ICP) qualified through training in infection control designated to direct the infection control program in any of the public and autonomous hospitals. It discloses that, the extent and seriousness of the problem is hardly recognized or acknowledged within the medical profession in this country. In some places infection control committee was constituted but they were not assigned defined role and they seldom organized activities directed to infection control. It can, therefore, be deducted that these committees mostly in public and autonomic hospitals were more ceremonial rather than active and purpose oriented. Surveillance of HCAIs is considered as a continuous process aimed mainly at remedy. It has to be implemented in real time as and when necessary until the practice as well as the outcome meets the recommended standards [18]. Surveillance of HCAIs was not found in half of the hospitals exclusively public. In such hospitals it is not possible to determine the scale of the problem and demonstrate improvement made over a time. These facilities at large were also unaware of existence of nationally directive and an updated list of disease reportable to the public health authority. This is among the most frequently seen characteristics of healthcare systems in most developing countries. These systems typically have limited and low quality data [19]. This study probed into some occupational health related practices at organizational and employee's level. It was found that none but one private hospital maintains Health Status Record of employees like immunization and testing of immunization status, a log of needle sticks, sharp injuries and other exposure events. Other hospitals did not also have post exposure evaluation and follow up procedures. There was also no immunization prophylaxis support from the institution. There was no instrument for management of job related illness and exposure to infectious disease, including policies for work restriction for personnel either infected or exposed. It can be concluded from these findings that most healthcare organizations are yet to catch up with organizational safety concepts and culture and be prepared to take responsibility for employee's safety. Inquiring about the organizational and personal culture of safe clinical practices, this study found that a great majority of the healthcare workers $(85.3 \%)$ washed their hand after removal gloves. Only a few of them performed hand hygiene techniques before direct patient contact $(14.3 \%)$ or after direct patient contact $(28 \%)$ whether or not using gloves. Half of the HCWs had complied with standard hand hygiene procedures before performing invasive procedure. A similar proportion (46\%) was also seen to wear gloves for procedures that might involve contact with blood and body fluid. Most of them removed gloves before moving to the next task and/or patient. A small number (6\%) was observed not to wash their hand even after contact with blood, body fluid and contaminated instruments. Intriguingly, most of these HCWs were educated and trained on indications, usage and importance of hand washing both with soap, water and hand rubbing with alcohol (71.3\%). Similarly, covering the cough at each time of the act was also infrequent (38\%). Only half of the HCWs were observed to wear PPE properly, although $63.3 \%$ of them mostly nurses and auxiliary workers claimed to have received training on proper selection and use of PPE. A few of them (19.3\%) from a private hospital only used utility gloves during handling of biological products and contaminated instruments. While disposing waste materials over a quarter of HCWS used the available coded containers. Only one private hospital periodically monitored and recorded adherence to hand hygiene and provided feedback to personnel regarding their performance. Sign posts at entrances of ward advising HCWs to cover their mouths/noses when coughing or sneezing were found in one private hospital only. In stating barriers to implementing successful knowledge based patient safety programs a common proposition may be lack of knowledge and training of HCWs. While lack of knowledge may play some role, availability of the knowledge by itself is not all. Institutional policy and oversight of the program may have equal if not greater role to play. This study shows a gap between knowledge and practices as well as lack of distinct institutional pursuance to observe safety instructions. It is conceivable that institutions, at policy, capacity building and implementation levels have distinct and clear roles to play in order to create and sustain an overall patient safety culture and environment. Laying such matters to irregular, isolated training and individual's responsibility can seldom be rewarded. Adding directions and motivations to education can only be expected to be partially effective. An integrated sector wise approach incorporating institutional commitment, policy and capacity building along with quality management initiative to ensure patient safety can be theoretically recommended and be practically viable [20]. Institutions should undertake a situation analysis and work out their own strategies in the context of available resources continuously seeking excellence in this direction. Overcoming institutional complacencies and resorting to such strategies are instrumental in continually improving healthcare outcomes [21]. This study was conducted in only 2 government, 2 autonomous and 2 private hospitals that were not randomly chosen. The study was only conducted in tertiary and academic hospitals, and a large output private hospital. It may be thought that number of hospitals, observed wards and healthcare workers are smaller in number consideration to the total healthcare system in respect of being representative. Therefore, there may be raised objections to using the findings as generalized to other government hospitals, private 
clinics or autonomous hospitals. It was a comprehension that Academic Hospitals are considered to be places of standard practices and are the focal points for dissemination of Good Practices. Patient safety, particularly infection control practices, cannot be optional and compared as a good, better and best. It is a continuous process for self-improvement for sustaining healthcare outcomes in the current perspective of knowledge and technology and this is more like a journey than destination. So, if it is possible to depict the current picture of practices of these hospitals, in terms of infection control, it can reflect the status of infection control as well as patient safety activities in other primary, secondary and tertiary level hospitals. This could set a starting point for entire healthcare service of Bangladesh as well as that of other developing countries for a sure journey towards a satisfactory and sustainable healthcare safety culture. Reassuringly, these findings are consistent with other studies in Bangladesh including tertiary hospitals that have reported on crowding in wards [10], infection proneness of physical environment and inadequacy infrastructure [16], improperness of waste disposal [22], poor hygiene and sanitation facilities and practices [16], lack of policies and active WHO guidelines [3], concern over injection and immunization safety [17], and respiratory hygiene [16]. This study brings into light only part of the big picture of the problem, and the concerns raised hare may essentially help all responsible to actually cogitate the extent and seriousness of the problem existing within the healthcare system.

\section{Recommendation}

Breaches in infection control measures in healthcare facilities can effect a person's healthcare course and outcome. It can have great impact on the commitment and image of a particular healthcare organization. Overall, inattention to infection control may undermine every health gain and investment made in the healthcare sector. Taking into consideration the prevailing scenario and the prospects of an effective infection control program this study proposes a set of actions that can be implemented easily and readily across countries without major resource implications.

1. National Authority and healthcare leaders should encompass infection control as a component of Patient Safety in their overall healthcare commitment. Public and professional awareness in respect of infection control should be raised in a compatible fashion.

2. Developing national accreditation body for hospitals that includes Infection Prevention and Control Program as a basic requirement. If healthcare-organizations fail to follow the standards, the Public Hospitals grants will be suspended and private hospitals license will be withheld.

3. Making Prevention and control of infections part of graduate and postgraduate medical and nursing curriculum.

4. Design a comprehensive multimodal National Infection Control Strategy with provision for research, system change, education and training, supervision and monitoring and feedback.

\section{Conclusions}

Public hospitals as well as academic and private service hospitals not only play a crucial role in ensuring healthcare services for the people of Bangladesh, but also have an academic role. The academic role assumes a greater importance as most of the HCWs at some point of their career undergo teaching and training in them. Therefore, good practices can be dispersed to every nook and corner of healthcare. In this attempt to reveal the current status of infection control practices in leading academic and private service hospitals, it was found that academic and private hospitals, whether government, autonomous or private in most cases do not have broad policy directions and could not establish a comprehensive and wellfunctioning infrastructure, program, processes and safety culture in terms of standard infection prevention and control practices, except one private service hospital. Routine practices of the healthcare workers as well as their behavior in terms of infection prevention and control was also not found to be conducive to the concepts of patient safety. In most of the hospitals of developing world, like Bangladesh infection control activities are limited by many constrains at all levels of healthcare. This study has created evidence in favor of absence of definitive infection prevention and control mechanism in most of the healthcare institutions and laid open avenues for health professional leaders and policy makers to divert their attention and technical resources to more genuine areas and cost-effective measures. A national commitment and comprehensive strategy together with creation of awareness, strengthening the knowledge-base, readjustment of structural design, implementation of appropriate teaching and training and instituting supervision, monitoring and feedback can be extremely contributory to changing the situation-from one of anguish to satisfaction, from despair to confidence and from laissez faire to organizational development. Viewing from academic perspective, this study has scoped to generate ample concern to policy makers, managers and leaders, healthcare workers, public and patients about the issue. Continuous research in this respect will unfold many other intricacies of importance. This will also encourage the institutions to assemble data to assess the size and nature of problem and to create a basis for formulating and monitoring their own infection control efforts.

\section{References}

[1] World Health Organization, 2005. World alliance for patient safety; Global patient safety challenge: 2005-2006, World Health Organization, Geneva, Switzerland.

[2] World Health Organization, 2005. The Global Patient Safety Challenge 2005-2006: clean care is safer care. Geneva, WHO. Available at: http://www.who.int/patientsafety/events/05/GPSC_Launch_E NGLISH_FINAL.pdf?ua $=1$ [Accessed on June 11, 2014].

[3] World Health Organization, 2006. The World Health Report 2006: working together for health. Geneva: WHO; 2005. Available at: http://www.who.int/whr/2006/en/. [Accessed on June 11, 2014]. 
[4] NHS England, 2011. English national point of prevalence survey on healthcare-associated infections and antimicrobial use, 2011: preliminary data. Available at: https://www.gov.uk/government/collections/healthcareassociated-infections-hcai-guidance-data-and-analysis. [Accessed on 9 September, 2015].

[5] National guideline on hand hygiene for prevention of hospital acquired infection, Hand hygiene \& Surgical Care, WHO Ban activity 2010-2011. Available at: http://www.hsmdghsbd.org/Documents/Doc_NATIONAL\%20 GUIDELINE\%20ON\%20HAND\%20HYGIENE.pdf. [Accessed on 8 February 2014].

[6] Center for Disease Control (CDC), 2011. Infection Prevention Checklist for Outpatient Settings: Minimum Expectations for Safe Care. <Available athttp://www.cdc.gov/HAI/pdfs/guidelines/ambulatory-carechecklist-07-2011.pdf> [Accessed on 10 May, 2014].

[7] Center for Disease Control (CDC), 2014. CDC/NHSN Surveillance Definitions for specific types of infections. Available http://www.cdc.gov/nhsn/pdfs/pscmanual/17pscnosinfdef_curr ent.pdf. [Accessed on 1 January, 2014].

[8] APIC, 2013. Infection Surveillance, Prevention and Control Program (ISPC): Brief History, EPI: 101. Available at: $<$ http://www.health.nv.gov/PDFs/Infections/ISPC.pdf $>$ [Accessed on 11 May, 2014].

[9] ASC Infection Control Surveyor Worksheet, 2013. Available at: $\quad<w w w . c m s . g o v / R e g u l a t i o n s-a n d-$ Guidance/.../som107 exhibit 351.pdf $>$ [Accessed on 13 April, 2014].

[10] Faruquzzaman, 2011. Positive associations of nosocomial infections in surgical ward with etiological clinical factors. BratislLekListy, 112 (5), pp 273-277.

[11] Darmstadt GL, Ahmed ASMNU, Saha SK, Chowdhury MAKA, Alam MA, Khatun M, Black RE and Santosham M, 2005. Infection control practices reduce nosocomial infections and mortality in preterm infants in Bangladesh. Journal of Perinatology, 25, pp 331-335.

[12] Zimring $\mathrm{C}$ and Ulrich R, 2004. The Role of the Physical Environment in the Hospital of the 21st Century: a Once-in-alifetime Opportunity. Concord, CA: The Center for Health Design.
[13] Raka L and Osmani GM, 2012. Infection Control in Developing World. Faculty of Medicine, University of Prishtina \& National Institute of Public Health of Kosova, Prishtina Kosova. Available at http://cdn.intechopen.com/pdfswm/28878.pdf [Accessed on 1 May, 2015].

[14] Hasan Z, 2010. How big a challenge to initiate three basic infection control practices in hospitals of Bangladesh? Editorial, Bangladesh J Med Microbiol, 04 (02), pp 1-2.

[15] Ulrich RS, Zimring C, Barch XZ, Dubose J, Seo HB, Choi YS, Quan X and Joseph A, 2008. A review of research literature on evidence based healthcare design. HERD 1: 61-125.

[16] Icddr, b, 2012. Health and Science Bulletin, 10 (3), pp 9-15.

[17] Shill MC, Fahad BM, Sarker S, Dev S, Rufaka HK and Das AK, 2011. Injection Practices at Primary Healthcare Units in Bangladesh: Experience at Six Upazilla Health Complexes. Australia's Med J, 41, pp 26-42.

[18] Sarma, JB and Ahmed, GU, 2010. Infection control with limited resources: why and how to make it possible? Indian Journal of Medical Microbiology, 28 (1), pp 11-16.

[19] Allegranzi B, Nejad SB, Combescure C, Graafmans W, Attar H, Donaldson L and Pittet D, 2011. Burden of endemic health care-associated infection in developing countries: systematic review and meta-analysis. The Lancet, 377, pp 228-241.

[20] Department of Health, 2006. The Health Act 2006, Code of Practice for the Prevention and Control of Health Care Associated Infections, 1st October 2006. Available at http://www.rcpath.org/Resources/RCPath/Migrated\%20Resou rces/Documents/M/Health\%20Act $\% 202006 \% 20$ Code $\% 20$ of $\%$ 20 Practice $\% 20$ for $\% 20$ the $\% 20$ prevention $\% 20$ and $\% 20$ control $\% 20 \mathrm{of} \% 20$ healthcare.pdf [Accessed on 28th August 2014].

[21] Boyce JM and Pittet D, 2002. Guideline for hand hygiene in healthcare settings. MMWR, 51 / RR-16; 1-44. Available at: www.cdc.gov/mmwr/preview/mmwrhtml/rr5116a1.htm [Accessed on 10 January, 2014].

[22] Nessa K, Quaiyum M A, Khuda B, 2001. Waste management in healthcare facilities: a review. ICDDR, B: Centre for Health and Population Research, Working Paper No. 144. 